
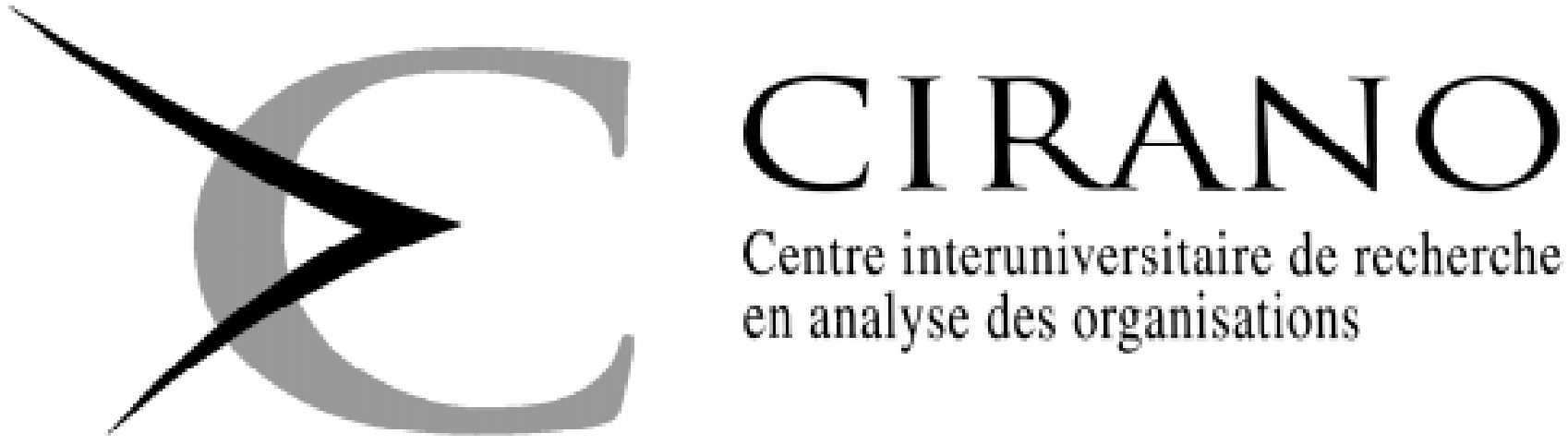

Centre interuniversitaire de recherche en analyse des organisations

Série Scientifique

Scientific Series

98s-40

Monetary Policy Rules with

Model and Data Uncertainty

Eric Ghysels, Norman R. Swanson, Myles Callan 


\section{CIRANO}

Le CIRANO est un organisme sans but lucratif constitué en vertu de la Loi des compagnies du Québec. Le financement de son infrastructure et de ses activités de recherche provient des cotisations de ses organisations-membres, d'une subvention d'infrastructure du ministère de l'Industrie, du Commerce, de la Science et de la Technologie, de même que des subventions et mandats obtenus par ses équipes de recherche. La Série Scientifique est la réalisation d'une des missions que s'est données le CIRANO, soit de développer l'analyse scientifique des organisations et des comportements stratégiques.

CIRANO is a private non-profit organization incorporated under the Québec Companies Act. Its infrastructure and research activities are funded through fees paid by member organizations, an infrastructure grant from the Ministère de l'Industrie, du Commerce, de la Science et de la Technologie, and grants and research mandates obtained by its research teams. The Scientific Series fulfils one of the missions of CIRANO: to develop the scientific analysis of organizations and strategic behaviour.

\section{Les organisations-partenaires / The Partner Organizations}

-École des Hautes Études Commerciales

-École Polytechnique

- Université Concordia

- Université de Montréal

- Université du Québec à Montréal

- Université Laval

- Université McGill

- MEQ

- MICST

- Alcan Aluminium Ltée

- Banque Nationale du Canada

- Bell Canada

- Caisse de dépôt et placement du Québec

- Développement des ressources humaines Canada (DRHC)

- Egis

- Fédération des caisses populaires Desjardins de Montréal et de l'Ouest-du-Québec

- Hydro-Québec

- Imasco

- Industrie Canada

- Microcell Labs inc.

- Raymond Chabot Grant Thornton

- Téléglobe Canada

- Ville de Montréal

(C) 1998 Eric Ghysels, Norman R. Swanson et Myles Callan. Tous droits réservés. All rights reserved. Reproduction partielle permise avec citation du document source, incluant la notice @.

Short sections may be quoted without explicit permission, provided that full credit, including $\odot$ notice, is given to the source.

Ce document est publié dans l'intention de rendre accessibles les résultats préliminaires de la recherche effectuée au CIRANO, afin de susciter des échanges et des suggestions. Les idées et les opinions émises sont sous l'unique responsabilité des auteurs, et ne représentent pas nécessairement les positions du CIRANO ou de ses partenaires.

This paper presents preliminary research carried out at CIRANO and aims to encourage discussion and comment. The observations and viewpoints expressed are the sole responsibility of the authors. They do not necessarily represent positions of CIRANO or its partners. 


\title{
Monetary Policy Rules with Model and Data Uncertainty*
}

\author{
Eric Ghysels ${ }^{\dagger}$, Norman R. Swanson ${ }^{\ddagger}$, Myles Callan ${ }^{\S}$
}

\section{Résumé / Abstract}

\begin{abstract}
Nous étudions l'impact de l'incertitude par rapport aux données, la spécification du modèle ainsi que les paramètres sur des règles de décisions de politique monétaire. Notre analyse est fondée sur le modèle de Taylor et les règles de politique monétaire qui en découlent. Nous utilisons une banque de données qui contient l'historique des données macro-économique telles qu'elles ont été publiées et révisées à travers le temps. Ainsi notre étude est en temps réel et respecte la chronologie des données que les protagonistes de la politique avaient à leur disposition à travers le temps. Nous étudions différents mécanismes de calibrage et d'apprentisage par moyen d'estimation.

We examine the prevalence of data, specification, and parameter uncertainty in the formation of simple rules which mimic monetary policy-making decisions. Our approach is to build real-time datasets, simulate a real-time policysetting environment, and provide a set of prescriptions and diagnoses which are useful not only within the context on monetary policy rules, but also within the context of the application of real-time data to macroeconomics in general. Some of our findings can be summarized as follows. First, while our version of "calibration" is better than naive estimation, both are dominated by an approach to rule formation based on adaptive least squares learning using real-time data. Second, it appears that rules based on seasonally unadjusted data are more reliable than when seasonally adjusted data are used. Finally, it does not pay to use data which are too preliminary. Indeed, it appears that it would be in the best interest of policymakers to wait until some of the data uncertainty associated with preliminary data has been removed by the revision process. Although some rules require more patience than others, a prescription based on our best-performing rule points to a waiting period of 9 months for monthly data, which in turn leads to around a $50 \%$ increase in precision.
\end{abstract}

Mots Clés : Révision des données, crédibilité des politiques monétaires, attentes rationelles et adaptives, données en temps réel

\footnotetext{
* Corresponding Author: Norman R. Swanson, Department of Economics, 521 Kern Graduate Building, Pennsylvania State University, University Park, PA 16802, United States. e-mail: nswanson@ psu.edu We wish to thank Dean Croushore, Lars Hansen, Glen Rudebusch and Thomas Sargent for stimulating conversations during the writing of the paper, and Brian Preslopsky for supplying us with target federal funds rate data. Swanson thanks the National Science Foundation (grant number SBR-9730102) for research support.

${ }^{\dagger}$ Pennsylvania State University and CIRANO

* Pennsylvania State University

$\S$ Pennsylvania State University
} 
Keywords : Data revision process, monetary authority credibility, predictive ability, adaptive and rational expectations, real-time data

JEL : C82, C53, C22 


\section{Introduction}

In academic circles, model and data uncertainty are rarely accounted for when monetary policy decision-making is discussed. By model uncertainty, we mean that the specification and/or parameters of a model are no longer assumed to be fixed and known. While ignoring this type of uncertainty often leads to tractable models which are easily analyzed, it may also paint a picture of the world which is oversimplified. By data uncertainty, we mean that first released data are often noisy in the sense that incomplete and/or erroneous initial information has been used in their construction. Indeed, it may take many years of revisions before data are considered final. Furthermore, actual policy decisions are made in a real-time setting using preliminary and/or partially revised data. Thus, questions relating not only to which variables should be used, but also to which data releases should be used, make the process of policymaking much more complex than is typically assumed in abstract models of monetary policy. In this paper we consider the above issues by examining monetary policy-rules using adaptive and recursive learning based on least squares, and using data which are available in real-time.

Uncertainty in policy models is an issue which has recently received some attention in the literature, both from the perspective of model misspecification and from the perspective of learning. Examples of papers in this area include Anderson, Hansen and Sargent (1997), Chung (1990), Granger and Deutsch (1992), Hansen and Sargent (1998), Marcet and Nicolini (1997), and Sargent (1998). Related papers in the area of learning are: Bray (1982), Bray and Kreps (1987), Kuan and White (1994), Marcet and Sargent (1989a,b), and Woodford (1990), while a review of the learning literature is in Marimon (1997). Anderson et al. (1997) and Hansen and Sargent (1998) consider discrete and continuous time optimal policy control models where decision makers assume that their models are misspecified, and adopt robust strategies which are meant to hedge against certain types of model misspecification. In particular, closed form policy rules are formulated which are a function of a robustness parameter. The robustness parameter, in turn, resembles commonly used measures of risk aversion. In this approach, decision-makers no longer take for granted that their model is: (1) true, in the sense that their model coincides with the underlying data generating process, (2) known by the decision-maker, and (3) fixed or time invariant. In the same spirit as Anderson et al. (1997), although less formally, Granger and Deutsch (1992) examine the evaluation of policy decisions which arise when a particular economic variable is targeted. They propose numerous tests based on the comparison of actual target variable outcomes 
with forecast values arising from the implementation of competing policy models.

Despite the recent interest in model uncertainty, it should be stressed that the bulk of the literature on monetary policy rules assumes that models are known and correctly specified. Within this context, rational expectations assumptions play a central role, and have led to numerous powerful policy prescriptions. The seminal papers by Phelps (1967), Friedman (1968) and Lucas (1972) laid much of the groundwork for these new results. Implications of this work were profound regarding the natural rate theory and the temporary character of trade-offs between inflation and unemployment, for example. The policy implications were far reaching in many other dimensions as well. For example, the Lucas critique suggested that the common practice of fitting econometric models, and simulating policy outcomes was in general incorrect. Despite the Lucas critique, however, the old approach of estimating new econometric models, and hence of formulating new policy prescriptions each time new data became available remained much in use. As Sargent (1998a) points out, this quandry can in many ways be equated with the distinction between policymaking under adaptive versus rational expectations. Sargent also stresses that early findings concerning the sub-optimality of adaptive expectations assumptions were based on the analysis of models which were assumed to be correctly specified (i.e. without model uncertainty). For example, when all models are viewed as approximations Sargent shows that simple "adaptive" forecasting techniques based on rolling regressions, where parameters are updated at each point in time, actually yield forecasts which are not inferior to those based on "optimal" rational expectations theories. This result is perhaps surprising, given that the rolling regression approach is certainly not optimal in a standard utility optimizing representative agent framework.

In this paper we examine model and data uncertainty within the context of monetary policy rules. In particular, we focus on monetary policy rules in which a short-term interest rate (the federal funds rate) is used as the policy instrument, and the monetary authority targets inflation and output. The class of rules which we consider are commonly refered to as Taylor's rules (see Taylor $(1979,1993 \mathrm{a})$ ), and are motivated by the apparent existence of tradeoffs between inflation and output variability. Versions of these rules have been incorporated in and/or arise in a variety of different macroeconomic models. For example, Rotemberg and Woodford $(1997,1998)$ develop a rational expectations model with intertemporally optimizating agents in which various interest rate targeting rules arise as optimal responses of the monetary authority. This series of papers is not only important because monetary policy rules are shown 
to arise naturally when expected utility in a representative household is maximized, but also because the model allows for the computation of welfare measures for representative households under different monetary policy rule implementations. Based on their theoretical model, as well as on a thorough empirical evaluation, Rotemberg and Woodford (1998) find that low and stable inflation together with stable interest rates can be acheived when Taylor's rules of the type which we examine are augmented by including lagged federal funds rates. Many other extensions and variations of Taylor's rule have been proposed in recent years. For example, policy rules that focus on exchange rates or the money supply are alternatives to rules which focus on interest rates. Indeed, the recent literature on policy rules is large. A partial list of relevant papers includes: Ball (1997), Bryant, Hooper and Mann (1993), Cukierman (1995), Estrella and Mishkin (1998), Frankel and Chinn (1995), Fuhrer (1997), Fuhrer and Moore (1995), Hansen (1996), Henderson and McKibbin (1993), King and Wolman (1996), Levin, Wieland and Williams (1998), Matheny (1996), McCallum (1993,1997), and Taylor (1993b).

We take our policy rules as given, and do not rationalize them with respect to any particular macroeconomic model. Thus, we do not attempt to offer new insights into the usefulness of policy rules per se (see e.g. Taylor (1993a,b), Sargent (1998a)). Moreover, unlike Hansen and Sargent (1998), we do not examine the deeper issue of the effect of model uncertainty on the design of policy rules, as we do not concern ourselves with the specification of a theoretical model. Rather, our approach is to emphasize two related but different issues, namely (i) model uncertainty viewed through the lens of parameter uncertainty and model specification, and (ii) the availability and timing of data with which to examine and implement rules.

With regard to the former issue, it should perhaps be noted that most papers which empirically examine policy rules abstain from parameter estimation and instead resort to calibration. As Sargent (1998b) points out, this approach implicitly assumes that the model from which the policy rule is derived is an approximation. Indeed, Rotemberg and Woodford (1998), for example, are clearly aware of this issue, as they empirically examine not only optimal policy rules which derive from their theoretical model (when appropriately calibrated), but also a variety of other related rules which are essentially alternative versions of Taylor's rule. This approach is consistent with the argument that since the models under investigation are approximations, the policy rules are also approximations. Furthermore, the "best" approximation might change as new information becomes available, not only in the sense of shifting parameters but also in the sense of changing specifications. Along these 
lines, one is left wondering what effects parameter estimation (or more generally parameter uncertainty) and model specification, have on the empirical evaluation of policy rules. We attempt to quantify these effects by jointly assessing their impact on the evaluation of policy rules when parameters are fixed (or calibrated), when parameters are estimated at a given point in time, when parameters are re-estimated as new information becomes available (a form of adaptive learning), and when the variables to include in the policy rule are chosen anew at each point in time (changing model specification).

With regard to the latter issue, the importance of the timing and availability of the data which are used in the emprical evaluation of policy rules is crucial. In order to address this important issue, we use real-time datasets to replicate the information available to policy makers at any given point in time in the day-to-day process of policy setting. In this sense, we simulate a real-time policy setting environment. Our real-time data collection strategy ensures that "future information" due to the use of information which is temporally antecedent to the date under consideration is not (accidentally) incorporated into the dataset at the wrong point in time. This is particularly important for seasonally adjusted data, for example, as two sided filters are generally used in the construction of such data, and the reestimation of the filters after date $t$, using data from $t+1$ and $t+2$, say, results in a revised seasonally adjusted figure for $t$ which actually contains information which was available beyond period $t$. Before discussing the relative merits of using real-time datasets, however, it is worth pointing out that within the context of timing (or availability), economic data can easily be classified into three types: (1) Preliminary Data: These types of data consist of the first reported datum for each variable at each point in time. (2) Partially Revised or Real-Time Data: These types of data are much more difficult to collect than preliminary data, as they are made up of a full vector of observations at each point in time for each variable. (3) Fully Revised or Final Data: Final data are data which have been successively revised, and for which no further revisions will be made. This is the type of data that academics often have in mind when conducting economic time series studies, perhaps simply because it is data which is not subject to revision, and it is felt that if one could adequately forecast a fully revised figure, then there would be no need for further modeling. It is quite possible, however, that true final data will never be available for many economic series. ${ }^{1}$ Interestingly, most

\footnotetext{
${ }^{1}$ This is because benchmark and definitional changes are ongoing and may continue into the indefinite future, for example. Moreover, seasonal adjustment filters involve two-sided filters which in principle have infinite leads and lags.
} 
datasets which are constructed by applied economists clearly consist of a mixture of preliminary data, partially revised data, and final revised data, but are clearly not real-time. This is an issue which has not been completely overlooked in the literature. For example, Orphanides (1997) recognizes the importance of real-time data when evaluating policy rules, and examines monetary policy rules using quarterly real-time data for the period 1987-1992. Our approach differs from Orphanides' in a number of respects. In particular, we use monthly data over a period of more than 20 years, examine parameter as well as model specification uncertainty, and consider the effects of using seasonally adjusted versus unadjusted data. In related work, Maravall and Pierce (1983, 1986), Pierce (1981), Sargent (1989), Trivellato and Rettore (1986) and Swanson, Ghysels and Callan (1997), examine revision process errors, while Diebold and Rudebusch (1991), Fair and Shiller (1990) and Swanson and White $(1995,1997)$ point out that the comparison of econometric forecasts based on data from CITIBASE, for example, with forecasts made in real-time by professional forecasters (e.g. see Croushore (1993)) is invalid, strictly speaking, because real-time data are not used in the estimation of the econometric models.

There are a multitude of dimensions pertaining to the use of real-time data in policy rules. First, with real-time data we can mimic the effects of parameter uncertainty in actual policy setting, since we can estimate policy rules with data which were truly available at any given point in time. This is particularly important with seasonally adjusted data, as such data are subject to revisions based on two-sided filters. To appraise the impact of data uncertainty we examine policy rules using: (1) seasonally adjusted and unadjusted real-time data, (2) different vintages of data (i.e. first releases and various revisions) and (3) ex-post data (i.e. the latest currently available data, regardless of the vintage). Hence, our analysis is based on a very broad interpretation of data uncertainty.

Our findings can broadly be summarized as a set of prescriptions and diagnoses which are useful not only within the context of monetary policy rules, but also within the context of the application of real-time data to macroeconomics in general. A partial list of our prescriptions and diagnoses are as follows. Vintage matters in policy decision making. For example, it is clear that using only "final" data does not yield optimal decision rules. Thus, prediction precision and hence monetary authority credibility is affected by the vintage (or release) of data used. Adaptive least squares learning yields improved results. In particular, while "calibration" is better than naive estimation, both are dominated by an approach to policy rule formation based on adaptive least squares learning. Dynamic information sets are useful. Put another way, policy 
rules based on distributed lag polynomials of target variables outperform simpler rules. In addition, the correct application of real-time information leads to policy rule precision which is comparable to that achieved by the use of ex-post data. Thus, the use of the standard (ex-post) sorts of datasets routinely applied in empirical economics not only invalidates any claim that later empirical findings are representative of the real-time flow of events in the economy, but also yields no noteable performance enhancement. Seasonally unadjusted data are better. This may be surprising as it is often argued that seasonal adjustment filters extract the "relevant" component of the data (see e.g. Ghysels (1994)). However, even cursory examination of our policy simulation results reveals that rules based on seasonally unadjusted data are more reliable than when seasonally adjusted data are used. Moreover, unadjusted data are directly available and avoid filtering problems which are exagerated in real-time datasets. Our last main finding is the following. Patience pays off. In particular, it does not pay to use data which are too preliminary. Indeed, it appears that it would be in the best interest of policymakers to wait until some of the data uncertainty associated with preliminary data has been removed by the revision process. Although some rules require more patience than others, a prescription based on our best-performing rule points to a waiting period of 9 months for monthly data, which in turn leads to around a $50 \%$ increase in precision.

The rest of the paper is organized as follows. In Section 2 we broadly discuss monetary policy rules. Section 3 contains details of the datasets which we have constructed. Empirical considerations are discussed in Section 4, while our findings are presented in Section 5. Conclusions are gathered in the final section.

\section{A Brief Background of Monetary Policy Rules}

John Taylor, in his seminal 1979 paper, introduces nominal rigidities into a rational expectations framework, and derives a model of the macroeconomy in which monetary policy irrelevance does not hold. Optimal monetary policy in this setting exploits a second-order Phillips curve (i.e. a long-run trade-off between inflation and output volatility), implying that business cycle fluctuations can be reduced by increasing the variability of inflation through accommodating monetary policies. In addition, the most important policy instrument in the U.S. since the 1960's 
has arguably been the Federal Funds rate. ${ }^{2}$ Thus, it is not surprising that recent research in optimal monetary policy has focused primarily on the use of short-term interest rates as policy instruments. For example, Bryant, Hooper and Mann (1993) report on a series of policy rule simulations, in which short-term interest rates are adjusted in response to deviations (from predetermined targets) in (a) the exchange rate, (b) the money supply, (c) nominal output, and (d) a combination of inflation (or the price level) and real output. Their findings suggest that rules which target inflation and output are the most successful in terms of reducing and stabilizing output and price variability. Taylor (1993a) draws on this finding and suggests a simple interest rate policy rule:

$$
R_{t}=1+1.5 \pi_{t}+0.5 y_{t}
$$

where, $R_{t}$ is the federal funds rate, $\pi_{t}$ is the rate of inflation, and $y_{t}$ is the output gap (i.e. the percentage deviation of output from its long-run trend). ${ }^{3}$ With this rule, the monetary authority raises the Federal Funds rate if either inflation rises above a target rate (which is assumed to be 2 ) or if real output rises above its long-term trend, with equal weights applied in either case. Using quarterly data, Taylor demonstrates that this rule succesfully mimics U.S. monetary policy for the period 1987 to 1992. Since our analysis is based on monthly data we replicate his graphical evidence (see Figure 1) using real-time industrial production and the Consumer Price Index series. Even though Taylor's original analysis is not based on real-time data and uses quarterly data, our findings based on various versions of Taylor's rule generally agree with his observations.

In addition to Taylor's (1993a,b) evidence, other recent research which further explores rational expectations models with sticky prices suggests that simple policy rules succesfully mimic the dynamic properties of the economy (e.g. Fuhrer and Moore (1995), Fuhrer (1997) and Rotemberg and Woodford $(1997,1998)$ ). Fuhrer estimates the "optimal policy frontier" which dictates the optimal trade-off between deviations of inflation around a target and output around its potential. This tradeoff rises rapidily when the standard deviation of either inflation or output falls below $2 \%$, which suggests that a balanced policy is preferable. Also,

\footnotetext{
${ }^{2}$ See Bernanke and Blinder (1992), Bernanke and Mihov (1998) and Meulendyke (1990)) for related discussion and for a detailed account of recent U.S. monetary policy operations.

${ }^{3}$ It should be stressed that Taylor does not advocate this particular rule, and notes that "... simple, algebraic formulations of such rules cannot and should not be mechanically followed by policymakers" (Taylor (1993a, pp. 213)). However, we view (1) as his "best" specification.
} 
he shows that Taylor's (1979) model lies close to this optimal frontier. Rotemberg and Woodford (1998) suggest an alternate optimal policy, one that responds positively to both the lagged funds rate itself, with a parameter larger than one, and inflation. Rotemberg and Woodford (1998, pp. 52) conclude that: "Probably our most important conclusion is that a simple interest-rate feedback rule of the kind proposed by Taylor (1993) can achieve outcomes nearly as good as are achievable in principle by any policy, assuming that the commitment of the monetary authority to the rule can be made sufficiently credible"

A novel view of the history of U.S. monetary policy is proposed by Sargent (1998), in which a new form of adaptive expectations is introduced. The methodology is applied to the hypothesized "regime shift" that followed Paul Volker's election as chairman the Board of Governors of the Federal Reserve. Sargent suggests that the shift in policy associated with Volcker's chairmanship may not have come from a sudden adherence to a rational expectations philosophy but rather gradually by a learning process that was adaptive, driven by the accumulation of information on the success and/or failure of past policies. In particular, Sargent (1998, pp. 141) notes that: "The regime shifts occur, not from a change in the government's econometric or policy-making procedures, but from a change in the beliefs created by its econometric procedure"

Our approach is to combine Taylor's rule with Sargent's notion of adaptive learning. One dimension of our approach is that we use recursive estimation with fixed and increasing windows of data. These methods comprise a menu of alternative means by which we implement adaptive expectations, and thus emulate the real-time process of policymaking. In this sense, we generalize Taylor's (1993a) rule to address criticisms of the operationality of the rule. The criticisms which we are refering to have been raised, for example, by McCallum (1993) and Orphanides (1997). In particular, they note that versions of Taylor's rule which have been examined in the literature (i) are not operational due to their reliance on contemporaneous data, and (ii) are not comparable to actual policy setting scenarios because ex-post data which are not real-time are used to fit the rules. ${ }^{4}$ One feature of our approach is that

\footnotetext{
${ }^{4}$ As an example of what is meant by "real-time", consider the case of industrial production (IP). When constructing a real-time dataset for IP, then for January 1990, say, a complete sequence of data going back to the beginning of the sample, say January 1959, must be collected. Furthermore, the data must be collected as if one were in January 1990, so that the final datum collected is actually the preliminary figure for December of 1989 (if this preliminary figure is available yet), while the datum for January 1959 has been revised many times for a variety of reasons (e.g. updates, definitional changes, and benchmark revisions). The key here is that no information which only became available after January 1990 is incorporated in any of
} 
by making use of real-time data we are able to address issues relating to response times of policymakers to new information. For example, it is of interest to assess whether policy rules based on first available data better emulate actaul economic fluctuations than policy rules based on later releases of data for some given calendar period. In addition, we address the choice between the use of seasonally adjusted or unadjusted data. This is a relevant issue because the revision processes of these two varieties of data are generally very different (see above discussion). ${ }^{5}$

\section{Data}

In this section we present the details of our real-time datasets. The first subsection is devoted to a description of the data. In the second subsection we discuss our approach to constructing real-time measures of inflation and the output gap.

\subsection{Real-Time Datasets}

In the sequel we use four monthly U.S. time series. Two of the variables (the target and effective federal funds rates) are not subject to revision. The other two variables (industrial production and the consumer price index) are subject to revision, and real-time datasets for each of them (both seasonally unadjusted and adjusted) have been constructed. In particular, industrial production (IP) data for the period 1950:04 to 1998:03 have been gathered, while consumer price index (CPI) data for the period 1978:01 to 1998:03 have been gathered. It is worth noting that the data matrix for IP contains more than 170,000 nontrivial entries while the data matrix for the CPI contains more than 29,000 nontrivial entries. As discussed above, the large number of observations in our real-time datasets is due to the nature of the data collection - at each point in time an entirely new sequence of data is collected, going back to the beginning of the sample period. In order to further illustrate these

the IP figures in the real-time vector of observations corresponding to a release date of January 1990. Then, a whole new sequence of data beginning in January 1959 and ending with data available in February 1990 is collected. This procedure is continued for each observational period in the sample, so that a matrix of observations comprises our real-time time dataset.

${ }^{5}$ There have been a number of papers which examine the relative merits of using seasonally adjusted versus unadjusted data within the context of monetary policy. Much of this research has focussed on the impact of data uncertainty on monetary policy decisions (see e.g. Maravall and Pierce $(1983,1986)$ ), and on the impact of filter design on policy implementation (see e.g. Ghysels (1987)). In this paper we do not focus on filter design, but rather we revisit data uncertainty. 
features of our data, we reproduce the matrix structure of a generic realtime dataset in Table 1. The entries in the table are denoted $X_{t}(\tau)$, where the subscript $t$ refers to the release date of the data pertaining to period $\tau$, the date which is in parentheses. Therefore, the diagonal elements in the matrix correspond to the first released or preliminary data. For example, the first entry in Table 1 shows the May 1950 release of the April IP or CPI figure. Keeping $\tau$ fixed the first row in the table shows the series of revisions from $t=$ May 1950 up until the end of our dataset March 1998.

Both IP and CPI data are released on or around the 15th of each month, and a typical months' release of data for these variables is comprised of a first, or preliminary release for the previous month, and 1 to 5 months of revisions to data previously released. In addition, more comprehensive benchmark and base year revisions occur from time to time for each of these variables. Turning first to the IP data, the following details are worth noting. Seasonally adjusted and unadjusted IP figures are compiled by the Federal Reserve Board. The primary source for seasonally adjusted IP data is the Federal Reserve Bulletin. For unadjusted IP (before October 1995) the main source is the Bureau of Economic Analysis' publication Survey of Current Business. Additional data for these series were obtained from Federal Reserve monthly statistical releases. Federal Reserve releases for IP are called G.12.3 before May 1990, and G.17 thereafter. Recent releases, and a partial real-time dataset from 1972 onwards for seasonally adjusted data, can also be obtained from the Board of Governor's of the Federal Reserve's website (http://www.bog.frb.fed.us/releases). Also, for three of the major (benchmark) revisions to IP, the Federal Reserve Board released separate publications - (1) Industrial Production 1957-59 Base, (2) Industrial Production 1971 and (3) 1976 Revision.

Aside from typical monthly revisions to recently released data, there have various major updates to IP. Numerous updates are "benchmark" updates for which at least 10 years of data are revised. In the January 1997 benchmark update, it was announced that the primary feature of the benchmark update was to reformulate indexes based on weights that are updated annually rather than every five years, as had been previously done. In general, updates involve updating seasonal adjustment weights (for seasonally adjusted data) and incorporating more complete information on important individual series, while benchmark updates additionally revise series definitions. Another type of update is the base year change. Examples of dates for updates of these types are: July 1971, July 1985, March 1990 and January 1997. Each of these base year updates coincides with a benchmark update, and in fact there are only 
four recent benchmark updates which do not correspond to base year updates (October 1967, July 1976, January 1994, and January 1998). Recent updates which are not benchmark updates occured during June 1964, August 1965, October 1966, June 1972, June 1973, August 1977, July 1979, August 1980, August 1981, August 1986, September 1987, April 1993 and November 1994, for example. For IP, there are 3 missing entries due to two major revisions, they are November and December 1953 and March 1985. We replaced each missing observation with the first available data for that period (which in each case is the second release).

Our real-time dataset for seasonally adjusted CPI was constructed from Federal Reserve Bank of St. Louis publications. The main source of this data is National Economic Trends. However, recent releases of the CPI can be obtained from http://www.stls.frb.org/fred/dataindx.html. In general, benchmark revisions to the CPI occur every 12 months, at which time revisions to the data for the preceding 12 months are reported. There is one base year revision - January 1988 (see National Economic Trends, pp. iii - August 1988 for details.)

For unadjusted CPI data, the series is compiled by the Department of Labor. The sources for the data are the Survey of Current Business, and the Department of Labor Publications entitled Monthly Labor Review and Consumer Price Index Detailed Report. There have been 3 recent base year updates in January of 1971, 1988, and 1995. These base year updates coincide with benchmark updates. Current releases, and detailed information regarding this series are available at the Bureau of Labor Statistics' CPI website (http://stats.bls.gov/cpifact8.htm).

The remaining variables, the target federal funds rate and the effective federal funds rate (1979:10 to 1998:04), are available from the Federal Reserve Bank of St. Louis and the Board of Governors of the Federal Reserve, respectively. The target federal funds rate is the Board of Governors' announced target for the overnight rate on interbank loans - which is revealed following each Federal Open Market Committee (FOMC) meeting. Generally FOMC meetings are held 8 times a year, except in special circumstances. We constructed a monthly dataset for this series which corresponds to the timing of our IP and CPI datasets. To do this, we assign the appropriate federal funds rates to each month, given the release dates of the IP and CPI data, which are often the 15th of each month, and almost always between the 14th and 17th. Therefore, we align each announced change in the target federal funds rate with the latest months' release of IP and CPI data that was available to the Board of Governors at the time of their decision. The notation that we use reflects these timing issues. If we denote some particular 
target federal funds rate as $r_{t}$, the preliminary data release for this observation is denoted $X_{t-1}(\tau)$, where $\tau=(t-2)$, i.e. at the time of the Board's decision, $t$, the most recent information available - released at time $(t-1)$ - pertains to the calendar date $(t-2)$. In this way, it is the availability of information that defines our "calendar time". The effective federal funds rate is the actual overnight rate on interbank loans. Again, we construct a monthly dataset for this series that corresponds to our real-time datasets. In this case, for each month we calculate the average of the effective federal funds rate for the 4 weeks following the release date of IP and CPI data.

\subsection{Real-Time Inflation and Output Gap Measures}

In order to construct operational real-time measures of inflation and of the output gap, we begin by assuming that our data are "final" after 23 revisions, so that our variables are assumed not to change appreciably beyond the 24th release. In our analysis we consider first and twelveth differences of CPI. In particular, we form:

$\left.\pi_{t}(t-1)=1200\left(\log \left(C P I_{t}(\tau-1)\right)-\log \left(C P I_{t}(\tau-2)\right)\right)\right)$ or $\left.\pi_{t}(t-1)=100\left(\log \left(C P I_{t}(\tau-1)\right)-\log \left(C P I_{t}(\tau-13)\right)\right)\right)$,

where $\tau=t, t-1, t-2, \ldots$. We consider annualized monthly inflation because this corresponds to the standard data transformation used in many empirical studies. On the other hand, twelveth differenced CPI data are used in order to facillitate a comparison of real-time time policy simulation outcomes based on either seasonally adjusted or seasonally unadjusted data. As $\tau$ varies, we essentially construct two new inflation series for each release of CPI data. Our output gap variable is the deviation of industrial production from its loglinear trend. Industrial production trend regressions are estimated using samples of 6-12 years of data, and as our empirical results were found to be qualitatively similar in all cases, we use 9 years of data for output gap calculations hereafter. In addition, we use real-time data in all trend regressions, and include seasonal dummy variables when constructing gap estimates based on seasonally unadjusted data. Thus, we construct the output gap as: $y_{t}(t-1)=100\left(\log \left(I P_{t}(\tau-1)\right)-\log \left(\widehat{I P}_{t}(\tau-1)\right)\right)$, where $\widehat{I P}_{t}(\tau-1)$ is the forecast of trend output based on information available at time $t-1$, and $\tau=t, t-1, t-2, \ldots$. 


\section{Real-Time Policy Strategies}

Along the lines discussed in section 2, we examine various real-time versions of Taylor's rule. These rules can be summarized as follows, where $m$ denotes the vintage of data used, $m$ is a fixed integer between 2 and 25, and $t$ indexes the horizon over which the policy rule is implemented: Rule 1: $R_{t}=1+1.5 \pi_{t-1}(t-m)+0.5 y_{t-1}(t-m)$,

Rule 2: $R_{t}=\hat{a}_{0}+\hat{b}_{1} \pi_{t-1}(t-m)+\hat{c}_{1} y_{t-1}(t-m)$,

Rule 3: $R_{t}=\hat{a}_{0}+\sum_{j=0}^{p_{1}} \hat{b}_{j} \pi_{t-1}(t-j-m)+\sum_{j=0}^{p_{2}} \hat{c}_{j} y_{t-1}(t-j-m)$,

Rule 4: $R_{t}=\hat{a}_{0}+\sum_{j=0}^{p_{1}(t-1)} \hat{b}_{j} \pi_{t-1}(t-j-m)+\sum_{j=0}^{p_{2}(t-1)} \hat{c}_{j} y_{t-1}(t-j-m)$,

Rule 5: $R_{t}=\hat{a}_{0}+\sum_{j=1}^{p_{1}} \sum_{k=j-1}^{p_{2}} \hat{b}_{j k} \pi_{t-j}(t-k-m)+\sum_{j=1}^{p_{3}} \sum_{k=j-1}^{p_{4}} \hat{c}_{j k} y_{t-j}$ $(t-k-m)$.

In Rules 1-5, $R_{t}$ is a short-term interest rate instrument (in our case either the effective or target Federal Funds rate), $\pi_{t}$ is the rate of inflation, and $y_{t}$ is the output gap. Notice that for Rules 1-2, only one vintage of data is used, and this data is always released at time $t-1$ and is thus available at time $t$. As the vintage, $m$, varies between 2 and 25 , twenty four different versions of these rules exist, leading to twenty-four real-time policy simulations for each rule. Rules 3 and 4 are the same as Rules 1 and 2, except that a sequence of different vintages of the target variables which are all released at time $t-1$ are incorporated in the policy rule. Recall that the different vintages correspond to updates of historical data. Rule 5 not only fixes a vintage "starting point" (as do Rules 1 to 4), but also allows previous releases of data for the same calendar time observation to be used by policy setters. This rule, thus, allows for every dimension of our real-time datasets to be used in the construction of policy rules.

Exentions to Rules 2-5 which include lagged values of the short-term interest rate instrument are given as follows:

Rule 6: $R_{t}=\hat{a}_{0}+\hat{b}_{1} \pi_{t-1}(t-m)+\hat{c}_{1} y_{t-1}(t-m)+\hat{d} R_{t-1}$,

Rule 7: $R_{t}=\hat{a}_{0}+\sum_{j=0}^{p_{1}} \hat{b}_{j} \pi_{t-1}(t-j-m)+\sum_{j=0}^{p_{2}} \hat{c}_{j} y_{t-1}(t-j-m)+$ $\hat{d} R_{t-1}$,

Rule 8: $R_{t}=\hat{a}_{0}+\sum_{j=0}^{p_{1}(t-1)} \hat{b}_{j} \pi_{t-1}(t-j-m)+\sum_{j=0}^{p_{2}(t-1)} \hat{c}_{j} y_{t-1}(t-j-$ $m)+\hat{d} R_{t-1}$, 
Rule 9: $R_{t}=\hat{a}_{0}+\sum_{j=1}^{p_{1}} \sum_{k=j-1}^{p_{2}} \hat{b}_{j k} \pi_{t-j}(t-k-m)+\sum_{j=1}^{p_{3}} \sum_{k=j-1}^{p_{4}} \hat{c}_{j k} y_{t-j}$ $(t-k-m)+\hat{d} R_{t-1}$.

The above rules can all be interpreted as adaptations of (1) to a real-time setting. In Rule 1, the response coefficients are fixed. Hence, there is no parameter estimation by the monetary authority. One interpretation of Rule 1 is that it is an optimal solution to some calibrated macroeconomic model. Notice that for any given simulation (across $t$ ), Rule 1 involves one vintage of data (i.e. $m$ is fixed). Thus, by varying $m$ and comparing simulation results we are able to assess the relevance of different vintages (or releases) of economic data for setting policy. One aspect of this feature of Rule 1 is that by examining the performance of this rule across vintages, we can quantify the benefits associated with waiting for more precise updates of the relevant target variables.

As Taylor (1993a) points out, it is not clear whether the response coefficients in Rule 1 are optimal. For this reason, Rules 2 through 9 are based on estimated response coefficients. (In the sequel we use OLS in all of our estimations.) In our analysis, we consider three different coefficient estimation schemes. The schemes are based on the amount of data used in, and the frequency of, response coefficient estimation. In the first scheme, all parameters are estimated once at the beginning of each real-time policy simulation, and remain fixed thereafter. This scheme is refered to as the No Window case. In the second scheme (the Fixed Window case) we use fixed rolling 50 and 100 month realtime data windows to re-estimate response parameters before each new policy decision is made. The third scheme, our Increasing Window case, is the same as the Fixed Window case except that we use an increasing real-time data window to estimate the coefficients, beginning with a window width of 50 months. It should be stressed that these schemes are practically feasible from a policymaking perspective, as they only entail decisions made using information available in real-time.

The first rule which uses estimated coefficients is Rule 2 (or Rule 6 with lagged $R_{t}$ ). This rule has the same policy response structure as Rule 1 , but with estimated coefficients. By comparing Rule 1 and Rule 2 we are able to assess the relative merits of using estimated rather than calibrated response coefficients. As Rotemberg and Woodford $(1997,1998)$ show, however, optimal policy may involve distributed lag polynomials of target variables and policy instruments. Thus, we also consider various Rotemberg and Woodford type rules. First, Rule 3 (or Rule 7 with lagged $R_{t}$ ) defines $R_{t}$ as a function of $p_{1}$ vintages of $\pi$ and $p_{2}$ vintages of $y$, where $p_{1}$ and $p_{2}$ are selected using the Schwarz Information Criterion 
(SIC), and the maximum number of lags is $24 .{ }^{6}$ Notice although the use of the word lags refers to calendar time lags, by fixing the release date of our data at $t-1$, we ensure that the most up to date revisions of all lags of our target variables are used. In Rule $3, p_{1}$ and $p_{2}$ do not change as new information becomes available, but rather are based on a real-time "startup" sample of observations. Rule 4 (or Rule 8 with lagged $R_{t}$ ) is the same as Rule 3 , except that $p_{1}$ and $p_{2}$ are selected anew every time a policy decision is made. A comparison of Rule 3 and 4 thus allows us to assess the impact of parameter uncertainty (which occurs in Rules 3 and 4) and model specification uncertainty (which occurs only in Rule 4). Note that the type of model specification uncertainty which we consider is limited to lag order selection. ${ }^{7}$ Moreover, comparing Rule 3 or 4 with Rule 2 highlights the impact of including distributed lags dynamics in our policy rules, and comparing any of Rules 2-4 with Rule 1 allows us to assess the impact of parameter and/or specification uncertainty on policy rules. In summary, the different ways in which the various rules can be compared allows us to disentangle, at least to some extent, the different effects that parameter, specification and data uncertainty have on Taylor's rule.

Thus far, we have only discussed policy rules based on data which are available at time $t-1$. In particular, Rules 1 through 4 assume that optimal policy is based on a single release of data. For example, when the subscript on our target variables is $t-1$, only data available in period $t-1$ are used in policy formation. While these rules clearly entail real-time policy setting, they may be naiive in one sense. If policy setters believe that different releases of data for the same calendar period contain different information, then they may want to formulate rules based not only on different vintages of data released in $t-1$, but also on different vintages of data released in $t-2$, say. For example, if the first and second release observation for January of 1990 are formed using information sets which are nonnested, both variables may be useful to policy setters. Although this sort of scenario might seem surprising, Swanson, Ghysels and Callan (1997) find some evidence that it is indeed true. In order to allow for this eventuality, we also consider Rule 5 (or Rule 9 with lagged $R_{t}$ ), which mixes vintages and releases of data.

\footnotetext{
${ }^{6}$ Recall that when referring to "vintages" of data, we are referring to data available at some calendar date which have been revised. So that the $m^{t h}$ vintage of data available at time $t-1$ is the revised datum for period $t-m$.

${ }^{7}$ For example, although nonlinear rules might be relevant to policy-setters, they are not investigated.
} 


\section{$5 \quad$ Empirical Findings}

In order to facilitate the comparison of our rules, we report four different types of results. In particular, we examine (1) ex-ante mean squared errors and mean absolute percentage errors, (2) turning point predictibility, (3) parameter estimates and (4) model specifications. Our approach is to simulate a real-time policy setting environment. To do this we consider ex-ante policy evaluation periods of 50 and 100 months. In addition to our two policy evaluation periods, we examine seasonally adjusted and unadjusted data, output gap measures based on $24^{t h}$ vintage data and real-time data and the target and effective federal funds rate. Thus there are 32 different permutations of data which can be used in the construction of tables associated with (1) - (4) above.

In order to streamline the presentation of our findings, we omit various results that are either uninteresting, or compareable to other findings which we do report. First, we report results for a 50 month evaluation period with the effective federal funds rate and a real-time output gap measure. Results for the 100 month evaluation period, the target federal funds rate, and the $24^{\text {th }}$ vintage based output gap measure are qualitatively similar and are available upon request from the authors. Second, we report results only for Rules 1-5. Although ex-ante mean square error results, for example, are always better when lagged values of the policy instrument are used, our findings across rules, windows, and vintages remain qualitatively similar, and hence tabulated results for Rules 6-9 are omitted for the sake of brevity. Third, we omit tabular evidence based on first differenced data. As noted above, first differences were only used to examine seasonally adjusted data. We omit these results because our findings based on twelveth differences are superior to compareable results based on first differences. This finding is attributable to the fact that first differenced real-time data are considerably more noisy than real-time data based on twelveth differences. This is because the former type of data involve first and second vintages while the latter involve first and twelveth vintages, and twelveth vintage data are relatively more accurate than second vintage data. ${ }^{8}$ Finally, our evidence based on absolute percentage error loss measures does not differ from the evidence which we offer based on mean square error loss measures, and so is omitted for the sake of brevity.

Tables 2 through 8 summarize our main empirical findings. In order to get a feel for the data which using in our analysis, and in particular the importance of the revision process, we begin by providing various sum-

\footnotetext{
${ }^{8}$ This observation has been made previously by Maravall and Pierce (1983) in the context of the noisiness of preliminary seasonally adjusted data.
} 
mary statistics which are presented in Table $2 \mathrm{a}$. In this table, we report on two types of data revisions, called fixed and increasing width revisions. The fixed revisions are constructed as $X_{t+i}(t)-X_{t+i-1}(t)$, and the increasing width revisions are $X_{t+i}(t)-X_{t}(t)$, for $i=1, \ldots, 11,18$, and 24. Table 2a contains three panels, corresponding to adjusted and unadjusted industrial production as well as adjusted CPI, for which mean, variance, skewness and kurtosis figures are reported. ${ }^{9}$ Observe that the mean of fixed length revisions is significantly different from zero at a 95 percent level of confidence, for numerous vintages of data. This suggests there is systematic bias in revisions of our variables, and such information could in principle be used to increase the accuracy of preliminary releases. Notice also that based on increasing width revisions, the difference between "final" (i.e. $i=24$ ) and initial releases of data has mean bias which is significantly different from zero. This implies that a statistically significant correction could be made to all releases of the variables, prior to their final release. Finally, the skewness and kurtosis statistics reported in Table 2a suggest that data revisions are characterized by clear departures from normality. This may be due to the presence of outliers in the revision process, which implies that real-time policy setting based on recent releases of data may result in policy decisions which are quite different from those which would have been made, had we known the "final" data. Thus, the data revision process may be quite important for policy setting. A comprehensive analysis of the data revision process for our real-time datasets which includes plots of revision autocorrelation functions and discussion of the pattern of outliers in the data, for example, is given in Swanson, Ghysels and Callan (1997). As we use inflation and output gap variables in our subsequent analysis, we also present basic statistics which are analagous to those given in Table $2 \mathrm{a}$ for $\pi$ and $y$ (see Table $2 \mathrm{~b}$ ). The results based on Table $2 \mathrm{~b}$ are largely similar to those discussed above for the raw data, with the noteable exception that the incidence of significant mean revisions given in the second column of the table is reduced. However, note that the absolute magnitude of these revisions is actually quite large, suggesting that this finding may be due to the small sample sizes used in the construction of the statistics.

The rest of our empirical findings are presented in Tables 3 through 8. Our findings with regard to data uncertainty are reported in Tables 3-4 for seasonally adjusted data and Tables 6-7 for seasonally unadjusted data. Tables 5 (adjusted data) and 8 (unadjusted data) summarize our

\footnotetext{
${ }^{9}$ Table 2 does not contain summary statistics for revisions in seasonally unadjusted CPI data, as revisions occur infrequently, and primarily in conjunction with base year benchmark revisions.
} 
findings with regard to parameter and model uncertainty. In Tables 3 and 6 we report mean square errors (MSEs) associated with 50 real-time policy decisions. ${ }^{10}$ The first column of the table gives the vintage of the data. The calendar date of the data used in all rules is $t-1$, except for Rule 5 in which a mixture of calendar dates is used (see above). The second column in the table reports MSEs for Taylor's Rule (Rule 1). The next three panels report MSEs for Rules 2-5, where response coefficients and/or rule specifications vary, and where the "window" of observations used by policy setters is fixed, increasing, or nonexistent. Tables 4 and 7 are presented in the same way, except that so-called "Confusion Rates" are reported rather than MSEs. The confusion rate indicates the proportion of times that our policy decision correctly predicts the direction of change in realized interest rates. Thus, a value of 0.50 corresponds to a policy rule which captures directional changes in interest rates so poorly that were we to flip a coin, we could do equally well. ${ }^{11}$ Finally, Tables 5 and 8 report the average and standard deviation of the response coefficients associated with the target variables when Rule 2 is the policy tool. As in the previous tables, the first column of these tables reports the vintage of data used to implement the rule.

Based on the results in Tables 3-8, our findings can be summarized as follows:

\section{Vintage matters in policy decision making}

This finding is supported by noting that MSE values in Tables 3 and 6 are dependent upon vintage. In Tables 3 and 6, lowest MSE values are boldfaced for each rule. For instance, in Table 3, Rule 1, the MSE varies from 1.439 to 4.447 depending on vintage. Morevover, MSEs are not monotonically increasing as vintage increases. Thus, it is not clear whether only using "final" data produces optimal decision rules. In fact, notice that the lowest MSEs in Tables 3 and 6 are associated with a Fixed Window of data, and occur for relatively recent vintages. For example, for Rule 4 with the Fixed Window of data, the lowest MSE vintage is $t-11$ for adjusted data and $t-10$ for unadjusted data. In addition, notice that for the same rule and the Increasing Window of

\footnotetext{
${ }^{10}$ In the tables, the end of our sample is May, 1996, so that we do not exhaust our entire dataset, which ends in March, 1998. The reason for this is that we also carried out ex-post policy simulations (assuming that finalized data were known) in order to assess the accuracy of our ex-ante results (see below).

${ }^{11} \mathrm{~A}$ case could be made for using the target rather than effective federal funds rate when simulating confusion rates. Unlike the federal funds rate, the target rate contains a small number of discrete level shifts which are directly associated with policy decisions, while the effective rate is a smoothed version of the target rate which might also be impacted by market forces.
} 
data, the analogous lowest MSE vintages are $t-2$ and $t-3$. Thus, we have evidence that preliminary data are useful. ${ }^{12}$ It is important to note that the "MSE-best" vintage varies across rules. This is expected, given that our rules exploit the real-time information set differently. For example, it should be expected that the MSE-best vintage for Rule 2 is higher than the MSE-best vintage for Rule 3. This is indeed the case for all of our results, and follows because Rule 3 uses all information from vintage $m$ back, say, while Rule 2 only uses information for a given vintage.

\section{Adaptive least squares learning yields improved results}

Based on both seasonally adjusted and unadjusted data, the lowest MSE value for Rule 1 is higher than the lowest MSE values (except for Rule 2) when the Fixed and/or Increasing Window of data used (see Tables 3 and 6). This suggests that adaptive policy rule formation is useful. In particular, in the No Window case, where response coefficients are not updated, MSEs are actually worse than in Rule 1, where no estimation is done whatsoever. Thus, one might conclude based on this finding that "calibration" (i.e. Rule 1) is better than naiive estimation (i.e. the No Window case), but worse than adaptive least squares learning (i.e. the Fixed and Increasing Window cases).

\section{Dynamic information sets are useful}

In Tables 3 and 6, when comparing Fixed and Increasing Window cases, Rules 3 and 4 always "MSE-dominate" Rule 2. In fact, MSE-best values are reduced by more than $50 \%$ in the Fixed Window case when Rules 2 and 3 are compared. For example, based on unadjusted data (Table 6), the MSE-best value is 0.534 for Rule 2 and 0.149 for Rule 3, corresponding to a $72 \%$ increase in precision when dynamic information sets are used. ${ }^{13}$ This finding provides evidence that policy rules based on distributed lag polynomials of target variables may outperform simpler rules (see e.g. Rotemberg and Woodford $(1997,1998)$ for further evidence).

Further evidence that dynamic information sets are useful is given in Figure 1, where the ex-ante performance of Rules 1-4 for a Fixed Window of data is graphically illustrated. Even causual observation of

\footnotetext{
${ }^{12}$ This does not mean, that final data are not useful (except in the case of Rule 2 ), but rather that the dataset which is "MSE-best" must contain preliminary data, while it may also contain earlier vintages, including final data.

${ }^{13}$ Note also that the lower MSE in this case is obtained based on the use of an earlier vintage of data.
} 
the graphs is sufficient to see that Rules 3 and 4 perform better than Rule 2, and Rules 2-4 perform better than Rule 1. One way to check whether the graphical evidence provided in Figure 1 is indicitive of our policy rules being useful in practice (e.g. in the construction of monetary stance indexes and to establish monetary authority and hence monetary policy credibility) is to compare the ex-ante performance of the rules with analogous ex-post performance. By ex-post performance, we mean that only final revised data are used in the rules. We implement our ex-post analysis by using data released in April, 1998. Thus, all data in our ex-post sample prior to May, 1996 is final, while newer data has been revized fewer than 23 times, and hence is not final, according to our definition. Notice that this type of ex-post analysis is currently the norm rather than the exception in empirical economics, as data which have been revised many times are routinely downloaded from CITIBASE, for example, with no regard to the fact that these data, although representative of information at time $t$, say, were actually not available until time $t+i$ for $i$ large. Use of datasets of this sort clearly invalidates any claim that later empirical findings are representative of the real-time flow of events in the economy. Nevertheless, a comparison of our ex-ante policy simulation results with an ex-post policy simulation should yield evidence concerning the usefulness of ex-ante rules. Such evidence is given in Figure 2, where it is apparent the performance of our ex-ante rules is essentially as good as an analogous set of ex-post rules where finalized data are assumed known. This result holds across rules and window specifications. (Results for windows other than the Fixed Window reported on in Figure 2 are available upon request from the authors.) One reason for the seemingly excellent ex-ante performance of the rules relative to their ex-post counterparts is that adaptive least squares is used, so that response coefficients are allowed to "adjust" to the type of data used.

\section{Real-time specification flexibility pays off}

Rule 4 is the MSE-best rule based on both adjusted and unadjusted data. Thus, learning is useful in two respects. First, updating response coefficients is better than fixing coefficients (No Window versus Fixed and Increasing Window cases). Second, updating the order of the lag polynomial (model uncertainty) in real-time is better than fixing the specification (Rule 4 versus Rules 1,2,3, and 5).

Revision bias is not as important as the use of real-time data

This finding is based upon a comparison of MSE-best values for Rules 3 and 5 in Tables 3 and 6 , where it is clear that Rule 3 is MSE-best. 
Notice that Rule 3 is closest to Rule 5 as neither incorporates specification flexibility. Thus, Rule 5 directly augments Rule 3 by including the history of data revision in addition to different vintages of data. One caveat to this finding is that we cannot actually claim that the use of data is more important than revision bias, rather we can say that given real-time data, revision history adds nothing in terms of MSE.

\section{Seasonally unadjusted data are better}

This may be surprising as it is often argued that seasonal adjustment filters extract the "relevant" component of the data. If a time series is viewed as the sum of different unobserved components, then it is argued that the seasonal component is "irrelevant" (see e.g. Ghysels (1994)). However, what is often not recognized is that seasonal adjustment entails more frequent and larger data revisions than are associated with unadjusted data (see e.g. Maravall and Pierce (1983)). Since all of our data are annual differences, the numerical entries in Tables 3 and 6 are directly comparable. Even cursory examination of these tables reveals that the MSE-best unadjusted rules dominate the corresponding MSEbest adjusted rules. For example, the overall MSE-best value in all of our tables is 0.124 , which obtains when unadjusted data, Rule 4, and the Fixed Window of data are used. The corresponding entry based on adjusted data is 0.244 , which roughly twice that based on unadjusted data. A further assessment of the noisiness of preliminary seasonally adjusted data is obtained when one examines Rule 2, which does not incorporate lagged polynomial information sets, and which is clearly our simplest adaptive rule. In the Fixed Window case, a MSE of $1.630 \mathrm{ob}-$ tains with vintage $t-2$ when unadjusted data are used. The analogous figure based on adjusted data is 2.033. Furthermore, the MSE based on adjusted data does not decrease to 1.630 until vintage $t-8$, suggesting that many revisions are necessary in order to smooth out the noisiness associated with seasonally adjusted data. Thus, using unadjusted data in policy decisions is MSE-preferable. Moreover, unadjusted data are directly available. ${ }^{14}$

Confusion rate findings based on seasonally adjusted data are confused

Notice that all of our findings with respect to rule and data window selection and based on unadjusted data are the same when either MSE or confusion rate loss is used (see Tables 6 and 7). However, analogous

\footnotetext{
${ }^{14}$ It is also worth noting that the Sims (1974) and Wallis (1974) results on estimation with filtered data do not apply in our context, as interest rates are unfiltered so that seasonal adjustment impacts response coefficient estimates.
} 
findings based on adjusted data and confusion rate loss do not agree with comparable MSE results (see Tables 3 and 4). In particular, the "confusion rates-best" models (i.e. boldfaced entries) associated with Rule 1 in Table 4 are often lower that those associated with other rules in Table 4, regardless of which data window is used. This is clearly not the case with unadjusted data. If these sorts of conflicting findings occured regardless of data adjustment, one might be led to believe that either (a) the choice of loss function is crucial or (b) our empirical findings are not robust. Indeed, there is much evidence in the economic forecasting literature that (a) is important (see e.g. Granger (1969) and Leitch and Tanner (1991)). However, given that our results are robust to evaluation period and output gap specification, it seems more likely that the problem lies with the use of seasonally adjusted data. For example, it is known that filters of various types alter the comovements between economic series (see e.g. Canova (1998)). In summary, our findings are consistent with a conjecture that turning point prediction is more sensitive to filtering than is MSE-based prediction. This is sensible if one believes that unusual (or one-time) events drive turning points, as these types of events tend to manifest themselves as observational outliers, which trigger smoothing corrections in standard adjustment programs (e.g. X-11 and X-12, see Findley, Monsell, Bell, Otto and Cheng (1998) and Ghysels, Granger and Siklos (1996)).

Response coefficients are weakly sensitive to the choice of vintage

Our results with respect to response coefficient sensitivity are gathered in Tables 5 (adjusted data) and 8 (unadjusted data). The layout of these tables is slightly different from the other tables. We take Rule 2 as a starting point and select the MSE-best vintage for each data window (called $m_{\text {opt }}$ ). We then form rules as follows:

$$
R_{t}=\hat{a}_{0}+\hat{b}_{1} \pi_{t-m_{o p t}-j}\left(t-m_{o p t}\right)+\hat{c}_{1} y_{t-m_{o p t}-j}\left(t-m_{o p t}\right),
$$

where $j=1, \ldots, 24$. We use this rule instead of Rule 2 as it allows us seperate out the impact of parameter uncertainty from that of specification uncertainty - both are mixed together if one examines parameter evolution based on Rule 2. In particular, direct use of Rule 2 mixes parameter and specification uncertainty because the calendar lags used in the rule depend on the vintage. The mean of the response coefficients given in Tables 5 and 8 varies smoothly, relatively monotonically, and with little variability across $j$. Note that output response coefficients do not depend critically on the data window for seasonally unadjusted data (see Table 8), but are more sensitive to data window when adjusted data 
are used (see Table 5). Inflation response coefficients, however, appear to depend critically on the data window used, again with higher variability across window being associated with seasonally adjusted data. Thus, while parameter uncertainty is not prevalent, response coefficents depend on the data window used, and hence on rule design.

\section{Patience pays off}

It does not pay to use data which are too preliminary. Indeed, it appears that it would be in the best interest of policymakers to wait until some of the data uncertainty associated with preliminary data has been removed by the revision process. Although some rules require more patience than others, a prescription based on our MSE-best rule (Rule 4, Fixed Window, Unadjusted data) points to a waiting period of 9 months (see Table 6). In this particular case, waiting for 9 months results in a $58 \%$ MSE reduction, from 0.298 to 0.124 .

\section{Conclusions}

In this paper we have examined model and data uncertainty within the context of monetary policy rules. Particular emphasis was placed on two related but different issues, namely (i) model uncertainty viewed through the lens of parameter and specification uncertainty, and (ii) the availability and timing of data with which to examine and implement policy rules. In order to carry out our analysis we built a number of large real-time datasets and carried out a series of experiments within the context of a real-time policy setting environment. Our analysis indicated that there are a multitude of dimensions pertaining to the use of real-time data in an empirical macroeconomic setting. For example, within the context of simple rules we find that data vintage (or release) is important in rule formation, and adaptive least squares learning based methods are preferable to simpler rule formation startegies. In addition, noise produced by seasonal adjustment filtering is prohibitively large when measured in a variety of different ways, prompting us to conclude that the use of seasonally unadjusted data is preferable to the use of seasonally adjusted data. Finally, it appears to be in the best interest of empirical economists to wait until some of the data uncertainty associated with preliminary data has been removed by the revision process before formulating adaptive rules based on an empirical analysis of macroeconomic data.

It is our view that many of the prescriptions and diagnoses which we give in this paper are useful not only within the context of monetary 
policy rule construction, but also within the context of the application of real-time data to macroeconomics in general. Indeed, we believe that the importance of using real-time data has not yet been fully recognized in mainstream economics, and many empirical techniques rely too heavily on the presumption that economic data are final and readily available. The construction of monetary policy rules is only one example, although a very important one, of how data and model uncertainty become relevant when we attempt to gather together empirical findings which are representative of the real-time flow of events in the economy. 


\section{References}

Anderson, E., L.P. Hansen and T.J. Sargent, (1997), Robustness and Risk-Sensitivity in General Equilibrium, Working Paper, University of Chicago and Hoover Institution.

Ball, L., (1997), Efficient Rules for Monetary Policy, National Bureau of Economic Research Working Paper Number 5952.

Bernanke, B. and A. Blinder, (1992), The Federal Funds Rate and the Channels of Monetary Transmission, American Economic Review, 82, 901-921.

Bernanke, B. and I. Mihov, (1998), Measuring Monetary Policy, Quarterly Journal of Economics, 113, 869-902.

Bray, M., (1982), Learning Estimation and the Stability of Rational Expectations, Journal of Economic Theory, 26, 318-339.

Bray, M. and D. Kreps, (1987), Rational Learning and Rational Expectations, in G. Feiwel eds. Arrows and the Ascent of Modern Economic theory, New York University Press, New York.

Bryant, R.C., P. Hooper and C. Mann (1993), Evaluating Policy Regimes: New Research in Empirical Macroeconomics, Brookings Institution, Washington, D.C.

Canova, F., (1998), Detrending and business cycle facts Journal of Monetary Economics, 41, 475-512.

Chung, H., (1990), Did Policymakers Really Believe in the Phillips Curve? An Econometric Test, Ph.D. Dissertation, University of Minnesota.

Croushore, D., (1993), Introducing: The Survey of Professional Forecasters, Federal Reserve Bank of Philadelphia Business Review, NovemberDecember, 3-15.

Cukierman, A., (1995), Towards a Systematic Comparison Between Inflation Targets and Monetary Targets, in: L. Leiderman and L. Svensson eds., Inflation Targets, Centre for Economic Policy Research, London.

Diebold, F.X. and G.D. Rudebusch, (1991), Forecasting Output With the Composite Leading Index: A Real Time Analysis, Journal of the American Statistical Association, 86, 603-610.

Leitch G. and J.E. Tanner, (1991), Economic Forecast Evaluation: Profit Versus The Conventional Error Measures, American Economic Review, $81,580-590$. 
Estrella, A. and F. Mishkin, (1998), Rethinking the Role of NAIRU in Monetary Policy: Implication of Model Formation and Uncertainty, Discussion Paper, Columbia University.

Fair, R. and R. Shiller, (1990), Comparing Information in forecasts From Econometric Models, American Economic Review, 80, 375-389.

Findley, D. B. Monsell, W.R. Bell, M. Otto and B.-C. Chen, (1998), New Capabilities and Methods of the X-12-ARIMA Seasonal-Adjustment Program Journal of Business and Economic Statistics, 16, 127-152.

Frankel J. and M. Chinn, (1995), The Stabilizing Properties of a Nominal GNP Rule, Journal of Money, Credit and Banking, 27, 318-334.

Friedman, M., (1968), The Role of Monetary Policy, American Economic Review, 58, 1-17.

Fuhrer, J., (1997), Inflation/Output Variance Tradeoffs and Optimal Monetary Policy, Journal of Money, Credit and Banking, 29, 214-234.

Fuhrer, J. and J. Moore, (1995), Monetary Policy Trade-Offs and the Correlation Between Nominal Interest Rates and Real Output, American Economic Review, 85, 219-239.

Ghysels, E., (1987), Seasonal Extraction in the Presence of Feedback, Journal of Business and Economic Statistics, 5, 191-194.

Ghysels, E., (1994), On the Economics and Econometrics of Seasonality in C.A. Sims (ed.) Advances in Econometrics - Sixth World Congress, Vol. I, 257-316, Cambridge University Press.

Ghysels, E. C.W.J. Granger and P. Siklos, (1996), Is Seasonal Adjustment a Linear Data Transformation Process?, Journal of Business and Economic Statistics, 14, 374-386.

Granger, C.W.J., (1969), Prediction With a Generalized Cost of Error Function, Operational Research Quarterly, 20, 451-468.

Granger, C.W.J. and M. Deutsch, (1992), Comments on the Evaluation of Policy Models, Journal of Policy Modelling, 14, 497-516.

Hansen, E., (1996), Price Level Versus Inflation Targets in an Open Economy With Overlapping Wage Contracts, Working Paper, Reserve Bank of New Zealand.

Hansen, L.P. and T.J. Sargent, (1995), Discounted Linear Exponential Quadratic Gaussian Control, IEEE Transactions on Automatic Control, 40, 968-971. 
Hansen, L.P. and T.J. Sargent, (1998), Discounted Robust Filtering and Control in the Frequency Domain, Working Paper, University of Chicago and Hoover Institution.

Henderson, D. and W. McKibbin, (1993), A Comparison of Some Basic Monetary Policy Regimes for Open Economies: Implications of Different Degrees of Instrument Adjustment and Wage Persistence, CarnegieRochester Conference Series on Public Policy, 39, 221-317.

King, R.G. and A.L. Wolman, (1996), Inflation Targeting in a St. Louis Model of the 21st Century, The Federal Reserve Bank of St. Louis Review, 78, 83-107.

Kuan, C.-M. and H. White, (1994), Adaptive Learning with Nonlinear Dynamics Driven by Dependent Processes, Econometrica, 62, 1087-1114.

Leitch, G. and J.E. Tanner, (1991), Economic forecast Evaluation: Profits Versus the Conventional Error Measures, American Economic Review, 81, 580-590.

Levin, A., V. Wieland and J.C. Williams, (1998), Robustness of Simple Monetary Policy Rules Under Model Uncertainty, Working Paper, Federal Reserve Board.

Lucas, R.E. (1972), Econometric Testing of the Natural Rate Hypothesis, in: A. Eckstein eds., The Econometrics of Price Determination: Conference, October 30-31, 1970, Board of Governors of the Federal Reserve System, Washington.

Maravall, A. and D. Pierce, (1983), Preliminary-Data Error and Monetary Aggregate Targeting, Journal of Business and Economic Statistics, 1, 179-186.

Maravall, A. and D. Pierce, (1986), The Transmission of Data Noise Into Policy Noise in U.S. Monetary Control, Econometrica, 54, 961-979.

Marcet, A. and J. Nicolini, (1997), Recurrent Hyper Inflations and Learning, Working Paper, Pompeu Fabra University.

Marcet, A. and T.J. Sargent, (1989a), Convergence of Least Squares Learning Mechanisms in Self Referential, Linear Stochastic Models, Journal of Economic Theory, 48, 337-368.

Marcet, A. and T.J. Sargent, (1989b), Convergence of Least Squares Learning in Environments With Hidden State Variables and Private Information, Journal of Political Economy, 97, 1306-1322.

Marimon, M., (1997), Learning From Learning in Economics, in: D. Kreps and K. Wallace eds. Advances in Economics and Econometrics: 
Theory and Applications, Volume 1, Cambridge University Press, Cambridge.

Matheny, K., (1996), Output Targeting and an Argument for Stabilization Policies, Working Paper, Purdue University.

McCallum, B.T., (1993), Discretion Versus Policy Rules in Practice, Two Critical Points: A Comment, in: Carnegie-Rochester Conference Series on Public Policy, 39, 215-220.

McCallum, B.T., (1997), Issues in the Design of Monetary Policy, Working Paper, Carnegie Mellon University.

Meulendyke, A.-M., (1989), U.S. Monetary Policy and Financial Markets, Federal Reserve Bank of New York, New York.

Orphanides, A., (1997), Monetary Policy Rules Based on Real-Time Data, Working Paper, Board of Governors of the Federal Reserve System.

Phelps, E., (1967), Phillips Curves, Expectations of Inflation and Optimal Unemployment Over Time, Economica, 2, 22-44.

Rotemberg, J.J. and M. Woodford, (1997), An Optimization-Based Econometric Framework for the Evaluation of Monetary Policy, NBER Macroeconomics Annual, 12, 297-346.

Rotemberg, J.J. and M. Woodford, (1998), Interest-Rate Rules in an Estimated Sticky Price Model, Discussion Paper, Harvard Business School.

Sargent, T.J., (1989), Two Models of Measurements and the Investment Accelerator, Journal of Political Economy, 97, 251-287.

Sargent, T.J., (1998), The Conquest of American Inflation, Marshall Lecture Series, The University of Cambridge.

Sargent, T.J. (1998), Discussion of "Policy Rules for Open Economies" by Laurence Ball, Working Paper, University of Chicago and Hoover Institution.

Sims, C.A. (1974), Seasonality in Regression, Journal of the American Statistical Association 69, 618-626.

Swanson, N.R., (1998), Money and Output Viewed Through A Rolling Window, Journal of Monetary Economics, 41, 455-474.

Swanson, N.R., E. Ghysels and M. Callan, (1998), A Multivariate Time Series Analysis of the Data Revision Process for Industrial Production and the Composite Leading Indicator, Working Paper, Pennsylvania State University. 
Swanson, N.R. and H. White, (1995), A Model Selection Approach to Assessing the Information in the Term Structure Using Linear Models and Artificial Neural Networks, Journal of Business and Economic and Statistics, 13, 265-275.

Swanson, N.R. and H. White, (1997), A Model Selection Approach to Real-Time Macroeconomic Forecasting Using Linear Models and Artificial Neural Networks, Review of Economics and Statistics, 79, 540-550.

Taylor, J.B., (1979), Estimation and Control of an Econometric Model with Rational Expectations, Econometrica, 47, 1267-1286.

Taylor, J.B., (1993a), Discretion versus Policy Rules in Practice, CarnegieRochester Conference Series on Public Policy, 39, 195-214.

Taylor, J.B., (1993b), Macroeconomic Policy in the World Economy: From Econometric Design to Practical Operation, W.W. Norton, New York.

Trivellato, U. and E. Rettore, (1986), Preliminary-Data Errors and Their Impact on the Forecast Error of simultaneous-Equations Models, Journal of Business and Economic Statistics, 4, 445-453.

Wallis, K.F. (1974), Seasonal Adjustment and Relations Between Variables, Journal of the American Statistical Association 69, 18-31.

Woodford, M.M., (1990), Learning to Believe in Sunspots, Econometrica, $58,277-308$. 


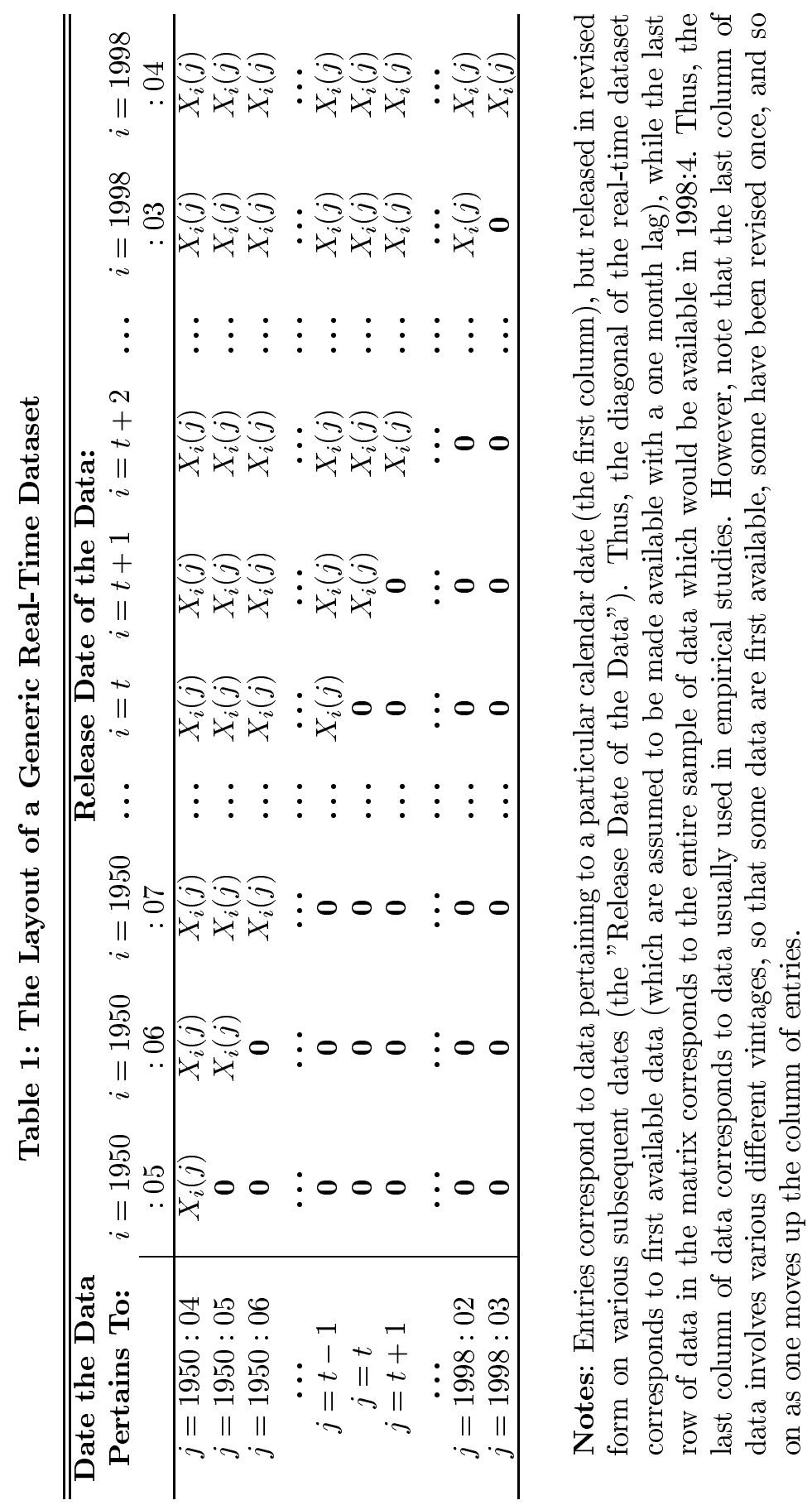


Table 2a: Real-Time Dataset Summary Statistics Seasonally Adjusted Industrial Production: 1979:2-1996:5

\begin{tabular}{|c|c|c|c|c|c|c|c|c|}
\hline & \multirow{2}{*}{$\begin{array}{l}\text { FIXED } \\
\text { Mean }\end{array}$} & \multicolumn{3}{|c|}{ WIDTH REVISIONS } & \multicolumn{2}{|c|}{ INCREASING } & \multicolumn{2}{|l|}{ WIDTH } \\
\hline & & $\begin{array}{r}\text { Var- } \\
\text { iance }\end{array}$ & $\begin{array}{r}\text { Skew- } \\
\text { ness }\end{array}$ & $\begin{array}{r}\text { Kurt- } \\
\text { osis }\end{array}$ & Mean & $\begin{array}{r}\text { Var- } \\
\text { iance }\end{array}$ & $\begin{array}{r}\text { Skew- } \\
\text { ness }\end{array}$ & $\begin{array}{r}\text { Kurt- } \\
\text { osis }\end{array}$ \\
\hline $\mathrm{i}=1$ & 0.076 & 0.398 & 13.79 & 19.59 & 0.076 & 0.398 & 13.79 & 19.59 \\
\hline $\mathrm{i}=2$ & 0.096 & 0.400 & 13.94 & 19.87 & $0.171 *$ & 0.848 & 9.776 & 9.846 \\
\hline $\mathrm{i}=3$ & 0.023 & 0.410 & 14.08 & 20.04 & $0.226^{*}$ & 0.899 & 9.790 & 9.837 \\
\hline $\mathrm{i}=4$ & $0.015^{*}$ & 0.475 & 14.11 & 20.21 & 0.221 * & 0.887 & 9.814 & 9.927 \\
\hline$i=5$ & $0.014^{*}$ & 0.409 & 14.11 & 20.93 & $0.218^{*}$ & 0.806 & 9.800 & 9.620 \\
\hline$i=6$ & $0.014^{*}$ & 0.469 & 14.10 & 20.69 & $0.224^{*}$ & 0.781 & 9.763 & 9.147 \\
\hline $\mathrm{i}=7$ & $0.014^{*}$ & 0.486 & 14.04 & 20.51 & $0.231^{*}$ & 0.829 & 9.795 & 9.686 \\
\hline$i=8$ & $0.015^{*}$ & 0.442 & 14.06 & 20.98 & $0.226^{*}$ & 0.804 & 9.784 & 9.446 \\
\hline $\mathrm{i}=9$ & $0.015^{*}$ & 0.407 & 14.07 & 20.12 & $0.232^{*}$ & 0.820 & 9.791 & 9.606 \\
\hline $\mathrm{i}=10$ & $0.015^{*}$ & 0.429 & 14.08 & 20.33 & $0.227^{*}$ & 0.827 & 9.786 & 9.543 \\
\hline $\mathrm{i}=11$ & 0.005 & 0.480 & 14.10 & 20.68 & $0.225^{*}$ & 0.801 & 9.788 & 9.537 \\
\hline $\mathrm{i}=12$ & $0.014^{*}$ & 0.426 & 14.11 & 20.20 & $0.225^{*}$ & 0.803 & 9.811 & 9.894 \\
\hline $\mathrm{i}=18$ & $0.015^{*}$ & 0.434 & 13.99 & 19.95 & $0.230^{*}$ & 0.840 & 9.770 & 9.448 \\
\hline $\mathrm{i}=24$ & 0.014 & 0.444 & 13.65 & 19.37 & $0.220 *$ & 0.821 & 9.718 & 9.853 \\
\hline
\end{tabular}

Seasonally Unadjusted Industrial Production: 1979:2-1996:5 FIXED WIDTH REVISIONS INCREASING WIDTH REVISIONS

\begin{tabular}{|c|c|c|c|c|c|c|c|c|}
\hline & Mean & $\begin{array}{c}\text { Var- } \\
\text { iance }\end{array}$ & $\begin{array}{r}\text { Skew- } \\
\text { ness }\end{array}$ & $\begin{array}{r}\text { Kurt- } \\
\text { osis }\end{array}$ & Mean & $\begin{array}{l}\text { Var- } \\
\text { iance }\end{array}$ & $\begin{array}{r}\text { Skew- } \\
\text { ness }\end{array}$ & $\begin{array}{r}\text { Kurt- } \\
\text { osis }\end{array}$ \\
\hline $\mathrm{i}=1$ & $-0.191^{*}$ & 4.444 & -0.145 & 3.454 & $-0.191^{*}$ & 4.044 & -0.145 & 3.454 \\
\hline$i=2$ & $-0.058^{*}$ & 0.110 & 1.347 & 28.31 & $-0.207^{*}$ & 4.126 & -0.142 & 3.404 \\
\hline$i=3$ & -0.016 & 0.078 & -6.073 & 81.67 & $-0.216^{*}$ & 4.390 & -0.413 & 4.213 \\
\hline $\mathrm{i}=4$ & -0.025 & 0.357 & -8.080 & 107.2 & -0.146 & 4.247 & -0.075 & 3.547 \\
\hline$i=5$ & $0.046^{*}$ & 0.288 & 13.07 & 180.4 & $-0.184 *$ & 4.060 & -0.154 & 3.435 \\
\hline$i=6$ & 0.007 & 0.017 & 12.33 & 169.2 & $-0.177 *$ & 4.077 & -0.153 & 3.417 \\
\hline$i=7$ & $0.014^{*}$ & 0.032 & 13.59 & 191.5 & $-0.176 *$ & 4.087 & -0.150 & 3.406 \\
\hline $\mathrm{i}=8$ & $0.015^{*}$ & 0.031 & 12.10 & 179.0 & $-0.180 *$ & 4.075 & -0.150 & 3.421 \\
\hline $\mathrm{i}=9$ & $0.012^{*}$ & 0.022 & 13.08 & 180.3 & $-0.179 *$ & 4.071 & -0.154 & 3.419 \\
\hline$i=10$ & $0.013^{*}$ & 0.026 & 12.43 & 167.4 & $-0.182 *$ & 4.078 & -0.161 & 3.435 \\
\hline$i=11$ & 0.009 & 0.018 & 12.75 & 174.5 & $-0.183 *$ & 4.093 & -0.167 & 3.454 \\
\hline $\mathrm{i}=12$ & 0.009 & 0.026 & 11.54 & 156.7 & $-0.181 *$ & 4.064 & -0.151 & 3.437 \\
\hline $\mathrm{i}=18$ & $<0.001$ & 0.001 & -12.56 & 99.04 & $-0.205 *$ & 4.121 & -0.163 & 3.408 \\
\hline $\mathrm{i}=24$ & -0.001 & 0.043 & -13.73 & 194.0 & $-0.220 *$ & 4.222 & -0.232 & 3.596 \\
\hline
\end{tabular}

Seasonally Adjusted Consumer Price Index: 1987:2-1996:5

\begin{tabular}{ccrrrrrrr} 
& \multicolumn{2}{c}{ FIXED } & \multicolumn{2}{c}{ WIDTH } & \multicolumn{2}{c}{ REVISIONS } & \multicolumn{3}{c}{ INCREASING WIDTH REVISIONS } \\
& Mean & Var- & Skew- & Kurt- & Mean & Var- & Skew- & Kurt- \\
& & iance & ness & osis & & iance & ness & osis \\
\hline $\mathrm{i}=1$ & $-0.003^{*}$ & $<0.001$ & -3.880 & 26.33 & $-0.003^{*}$ & $<0.000$ & -3.880 & 26.33 \\
$\mathrm{i}=2$ & $-0.003^{*}$ & $<0.001$ & -2.972 & 21.18 & $-0.007^{*}$ & 0.001 & -2.391 & 11.36 \\
$\mathrm{i}=3$ & $-0.004^{*}$ & $<0.001$ & -3.576 & 21.64 & $-0.006^{*}$ & 0.001 & -2.505 & 12.43 \\
$\mathrm{i}=4$ & $-0.003^{*}$ & $<0.001$ & -3.839 & 25.53 & $-0.004^{*}$ & $<0.000$ & -3.274 & 18.60 \\
$\mathrm{i}=5$ & $-0.001^{*}$ & $<0.001$ & -7.105 & 52.06 & $-0.003^{*}$ & 0.001 & -1.694 & 11.96 \\
$\mathrm{i}=6$ & $<0.001$ & $<0.001$ & -0.551 & 18.39 & $-0.003^{*}$ & 0.001 & -1.814 & 12.86 \\
$\mathrm{i}=7$ & -0.001 & $<0.001$ & -0.743 & 22.04 & $<0.000$ & 0.001 & 0.439 & 15.16 \\
$\mathrm{i}=8$ & $0.003^{*}$ & $<0.001$ & 3.904 & 30.62 & -0.001 & 0.001 & -0.169 & 16.37 \\
$\mathrm{i}=9$ & $0.002^{*}$ & $<0.001$ & 4.502 & 38.60 & $<0.000$ & 0.001 & 0.325 & 16.32 \\
$\mathrm{i}=10$ & $0.003^{*}$ & $<0.001$ & 4.560 & 36.19 & -0.002 & 0.001 & -0.410 & 13.74 \\
$\mathrm{i}=11$ & 0.001 & 0.001 & 0.241 & 23.66 & $-0.004^{*}$ & 0.001 & -1.577 & 14.09 \\
$\mathrm{i}=12$ & -0.001 & 0.001 & -1.865 & 25.46 & $-0.006^{*}$ & 0.001 & -3.363 & 16.47 \\
$\mathrm{i}=18$ & $-0.002^{*}$ & $<0.001$ & -3.018 & 21.14 & $-0.006^{*}$ & 0.001 & -2.837 & 13.68 \\
$\mathrm{i}=24$ & $<0.001$ & $<0.001$ & -5.155 & 22.52 & $-0.003^{*}$ & $<0.000$ & -3.880 & 26.33 \\
\hline
\end{tabular}


Notes to Table $2 \mathrm{a}:{ }^{*}$ denotes a mean value that is significantly different from zero based on a $95 \%$ confidence interval constructed using a heteroskedasticity and autocorrelation consistent variance estimator. Fixed width revisions are constructed as $\ln \left(X_{t+i-1}(t-2)\right)-$ $\ln \left(X_{t+i-2}(t-2)\right)$ and increasing width revisions are constructed as $\ln \left(X_{t+i-1}(t-2)\right)-\ln \left(X_{t-1}(t-2)\right)$, where $X$ is either IP or CPI. In these definitions, the subscript refers to the release date of the data, while the bracketed index denotes the the date to which the release pertains (see Table 1). For example, the " $i-2$ " rows in the table correspond to $\ln \left(X_{t+1}(t-2)\right)-\ln \left(X_{t}(t-2)\right)$ for the fixed width revisions. In this case, the second release for the period $t$ is subtracted from the third release for period $t$. For increasing width revisions, the " $i=2$ " rows correspond to $\ln \left(X_{t+1}(t-2)\right)-\ln \left(X_{t-1}(t-2)\right)$, so that the first release (or first available data) is subtracted from the third release for the period $t-2$. The sample period for which we present summary statistics is determined by our real-time simulation experiments. The period reported on for IP is longer than for CPI because additional IP data were needed in order to estimate trend lines for use in output gap construction. Results for our larger sample periods (from 1950 for IP and 1978 for CPI) are qualitatively similar, and are available upon request from the authors. The end period of the data is 1996:5, corresponding to the last interest rate observation used in our subsequent ex-ante analysis. This end date was used (as opposed to the actual end of our sample 1998:3) in order to facillitate an ex-ante versus ex-post comparison of policy rule performance (see discussion in Section 5). 
Table 2b: Vintages of the Output Gap and Inflation, Summary Statistics

Seasonally Adjusted Output Gap: 1990:2-1996:3

FIXED WIDTH REVISIONS INCREASING WIDTH REVISIONS

\begin{tabular}{|c|c|c|c|c|c|c|c|c|}
\hline & Mean & $\begin{array}{c}\text { Var- } \\
\text { iance }\end{array}$ & $\begin{array}{r}\text { Skew- } \\
\text { ness }\end{array}$ & $\begin{array}{r}\text { Kurt- } \\
\text { osis }\end{array}$ & Mean & $\begin{array}{c}\text { Var- } \\
\text { iance }\end{array}$ & $\begin{array}{r}\text { Skew- } \\
\text { ness }\end{array}$ & $\begin{array}{r}\text { Kurt- } \\
\text { osis }\end{array}$ \\
\hline$i=1$ & $-8.675^{*}$ & 540.7 & -0.830 & 5.743 & $-8.675^{*}$ & 540.7 & -0.830 & 5.743 \\
\hline$i=2$ & $-5.631^{*}$ & 384.2 & -1.109 & 9.198 & $-14.30^{*}$ & 1087 & -0.526 & 4.543 \\
\hline $\mathrm{i}=3$ & $-4.011^{*}$ & 187.0 & -3.779 & 33.96 & $-18.31^{*}$ & 1267 & -0.646 & 4.452 \\
\hline $\mathrm{i}=4$ & -0.192 & 122.2 & -7.887 & 86.90 & $-18.50^{*}$ & 1398 & -0.920 & 5.057 \\
\hline$i=5$ & -0.389 & 139.0 & -8.119 & 87.28 & $-18.89^{*}$ & 1625 & -1.140 & 5.991 \\
\hline$i=6$ & -0.873 & 87.56 & -9.754 & 104.1 & $-19.77^{*}$ & 1783 & -1.234 & 5.917 \\
\hline $\mathrm{i}=7$ & 0.097 & 34.03 & -3.703 & 58.49 & $-19.67^{*}$ & 1834 & -1.193 & 5.645 \\
\hline$i=8$ & 0.162 & 54.95 & -5.178 & 61.66 & $-19.51^{*}$ & 1946 & -1.135 & 5.243 \\
\hline $\mathrm{i}=9$ & 0.070 & 75.62 & 2.289 & 52.15 & -19.44 & 2087 & -1.002 & 4.802 \\
\hline$i=10$ & -0.323 & 97.71 & -0.336 & 35.42 & -19.76 & 2169 & -0.899 & 4.429 \\
\hline$i=11$ & 0.042 & 211.7 & 3.069 & 56.22 & $-19.72^{*}$ & 2347 & -0.763 & 4.058 \\
\hline$i=12$ & -1.281 & 151.9 & -8.149 & 79.83 & $-21.00 *$ & 2440 & -0.670 & 3.762 \\
\hline $\mathrm{i}=18$ & -0.556 & 28.02 & -1.987 & 27.74 & $-25.89^{*}$ & 2632 & -0.461 & 3.379 \\
\hline $\mathrm{i}=24$ & -2.474 & 527.2 & -7.995 & 76.15 & -33.06 & 3513 & -0.852 & 4.130 \\
\hline
\end{tabular}

Seasonally Unadjusted Output Gap: 1990:2-1996:3

FIXED WIDTH REVISIONS INCREASING WIDTH REVISIONS

\begin{tabular}{|c|c|c|c|c|c|c|c|c|}
\hline & Mean & $\begin{array}{c}\text { Var- } \\
\text { iance }\end{array}$ & $\begin{array}{r}\text { Skew- } \\
\text { ness }\end{array}$ & $\begin{array}{r}\text { Kurt- } \\
\text { osis }\end{array}$ & Mean & $\begin{array}{r}\text { Var- } \\
\text { iance }\end{array}$ & $\begin{array}{r}\text { Skew- } \\
\text { ness }\end{array}$ & $\begin{array}{r}\text { Kurt- } \\
\text { osis }\end{array}$ \\
\hline$i=1$ & $-7.375^{*}$ & 480.5 & 0.630 & 6.688 & $-7.375^{*}$ & 480.5 & 0.630 & 6.688 \\
\hline$i=2$ & -3.129 & 587.1 & 3.501 & 27.13 & $-10.50 *$ & 1095 & 1.293 & 8.607 \\
\hline $\mathrm{i}=3$ & -2.018 & 153.0 & 1.331 & 9.921 & $-12.52^{*}$ & 1165 & 1.103 & 7.251 \\
\hline $\mathrm{i}=4$ & $-4.046^{*}$ & 3228 & -10.51 & 114.8 & $-16.56^{*}$ & 4571 & -6.713 & 65.89 \\
\hline$i=5$ & 6.848 & 3534 & 10.37 & 112.0 & $-9.721^{*}$ & 1243 & 1.071 & 6.916 \\
\hline$i=6$ & 1.187 & 132.8 & 9.861 & 103.5 & $-8.534^{*}$ & 1313 & 1.006 & 6.365 \\
\hline $\mathrm{i}=7$ & 1.960 & 317.7 & 9.972 & 105.1 & -6.574 & 1639 & 1.477 & 8.046 \\
\hline$i=8$ & 1.914 & 301.9 & 10.245 & 109.7 & -4.660 & 1845 & 1.512 & 7.523 \\
\hline $\mathrm{i}=9$ & 0.416 & 276.6 & 5.994 & 76.21 & -4.245 & 2054 & 1.407 & 6.727 \\
\hline $\mathrm{i}=10$ & 0.887 & 286.6 & 8.896 & 97.76 & -3.358 & 2322 & 1.434 & 6.375 \\
\hline $\mathrm{i}=11$ & -0.123 & 328.4 & 2.660 & 56.88 & -3.481 & 2729 & 0.974 & 5.800 \\
\hline $\mathrm{i}=12$ & 0.503 & 337.4 & 7.622 & 84.59 & -2.978 & 3125 & 1.118 & 5.899 \\
\hline $\mathrm{i}=18$ & -1.255 & 157.7 & -10.62 & 116.0 & -9.481 & 4296 & 0.444 & 4.910 \\
\hline $\mathrm{i}=24$ & -1.750 & 204.6 & -8.509 & 77.65 & -16.22 & 4938 & 0.402 & 4.271 \\
\hline
\end{tabular}

Seasonally Adjusted Inflation: 1990:2-1996:3

FIXED WIDTH REVISIONS INCREASING WIDTH REVISIONS

\begin{tabular}{|c|c|c|c|c|c|c|c|c|}
\hline & Mean & $\begin{array}{c}\text { Var- } \\
\text { iance }\end{array}$ & $\begin{array}{r}\text { Skew- } \\
\text { ness }\end{array}$ & $\begin{array}{r}\text { Kurt- } \\
\text { osis }\end{array}$ & Mean & $\begin{array}{l}\text { Var- } \\
\text { iance }\end{array}$ & $\begin{array}{r}\text { Skew- } \\
\text { ness }\end{array}$ & $\begin{array}{r}\text { Kurt- } \\
\text { osis }\end{array}$ \\
\hline $\mathrm{i}=1$ & -0.086 & 1.326 & -2.231 & 31.21 & -0.086 & 1.326 & -2.231 & 31.21 \\
\hline $\mathrm{i}=2$ & -0.098 & 1.460 & -2.551 & 30.02 & -0.184 & 2.769 & -1.552 & 15.14 \\
\hline$i=3$ & $-0.455^{*}$ & 3.049 & -3.585 & 14.20 & $-0.639^{*}$ & 5.650 & -1.563 & 7.050 \\
\hline $\mathrm{i}=4$ & $-0.266^{*}$ & 1.913 & -5.038 & 27.37 & $-0.906^{*}$ & 7.220 & -1.374 & 5.282 \\
\hline $\mathrm{i}=5$ & 0.110 & 1.575 & 3.104 & 36.79 & $-0.795^{*}$ & 8.997 & -0.682 & 5.055 \\
\hline$i=6$ & -0.110 & 3.284 & -1.314 & 17.58 & $-0.906^{*}$ & 12.10 & -0.374 & 3.949 \\
\hline$i=7$ & -0.105 & 3.101 & -1.505 & 19.79 & $-1.011^{*}$ & 15.01 & -0.208 & 3.319 \\
\hline $\mathrm{i}=8$ & 0.196 & 5.539 & 1.709 & 27.36 & -0.815 & 20.95 & 0.194 & 3.930 \\
\hline $\mathrm{i}=9$ & 0.124 & 3.171 & 3.810 & 36.92 & -0.692 & 24.32 & 0.336 & 3.670 \\
\hline $\mathrm{i}=10$ & 0.265 & 4.620 & 3.742 & 27.87 & -0.427 & 29.31 & 0.429 & 3.317 \\
\hline$i=11$ & 0.297 & 13.741 & 3.280 & 32.00 & -0.130 & 43.31 & 0.795 & 4.867 \\
\hline $\mathrm{i}=12$ & 0.026 & 8.354 & -1.008 & 23.69 & -0.104 & 51.67 & 0.545 & 4.025 \\
\hline $\mathrm{i}=18$ & 0.102 & 1.279 & 10.82 & 119.0 & -0.432 & 64.37 & 0.189 & 3.428 \\
\hline $\mathrm{i}=24$ & -0.015 & 0.029 & -10.82 & 119.0 & -0.262 & 64.00 & 0.148 & 3.442 \\
\hline
\end{tabular}


Notes to Table 2b: See notes to Table 2a. Fixed width revisions are constructed as $\left(\hat{X}_{t+i-1}(t-2)-\hat{X}_{t+i-2}(t-2)\right) * 100$ and increasing width revisions are constructed as $\left(\hat{X}_{t+i-1}(t-2)-\hat{X}_{t-1}(t-2)\right) * 100$, where $\hat{X}$ is either the output gap or inflation. The sample period reported corresponds to the period used in the 50 month policy simulation reported on in subsequent tables. 


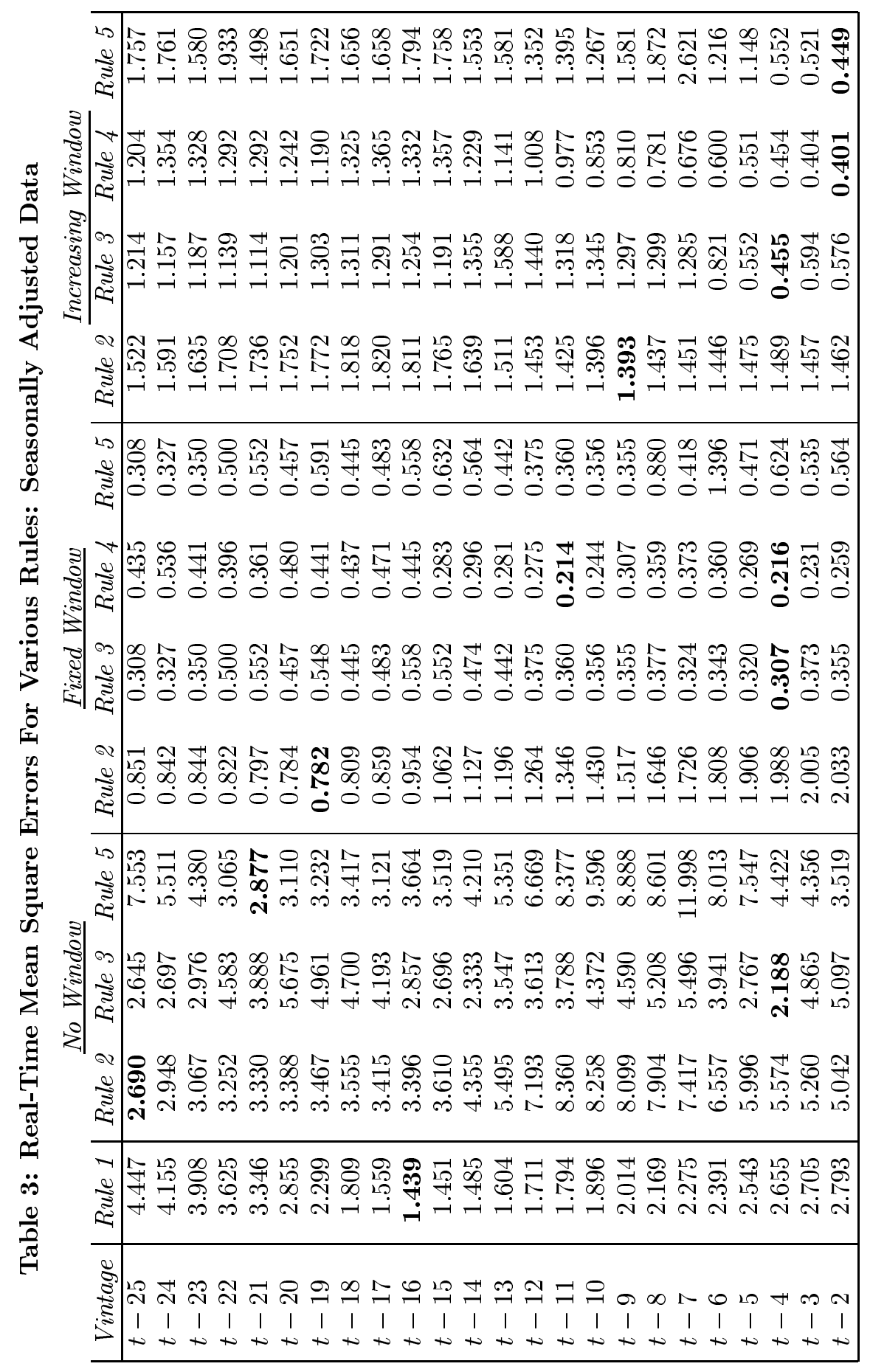




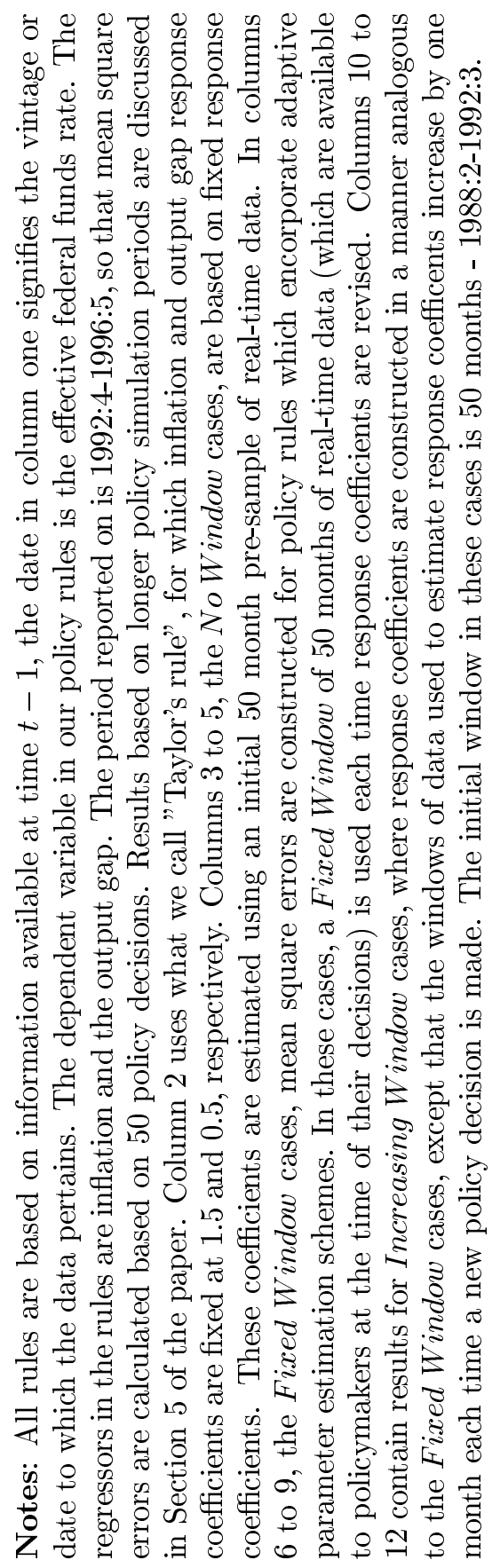




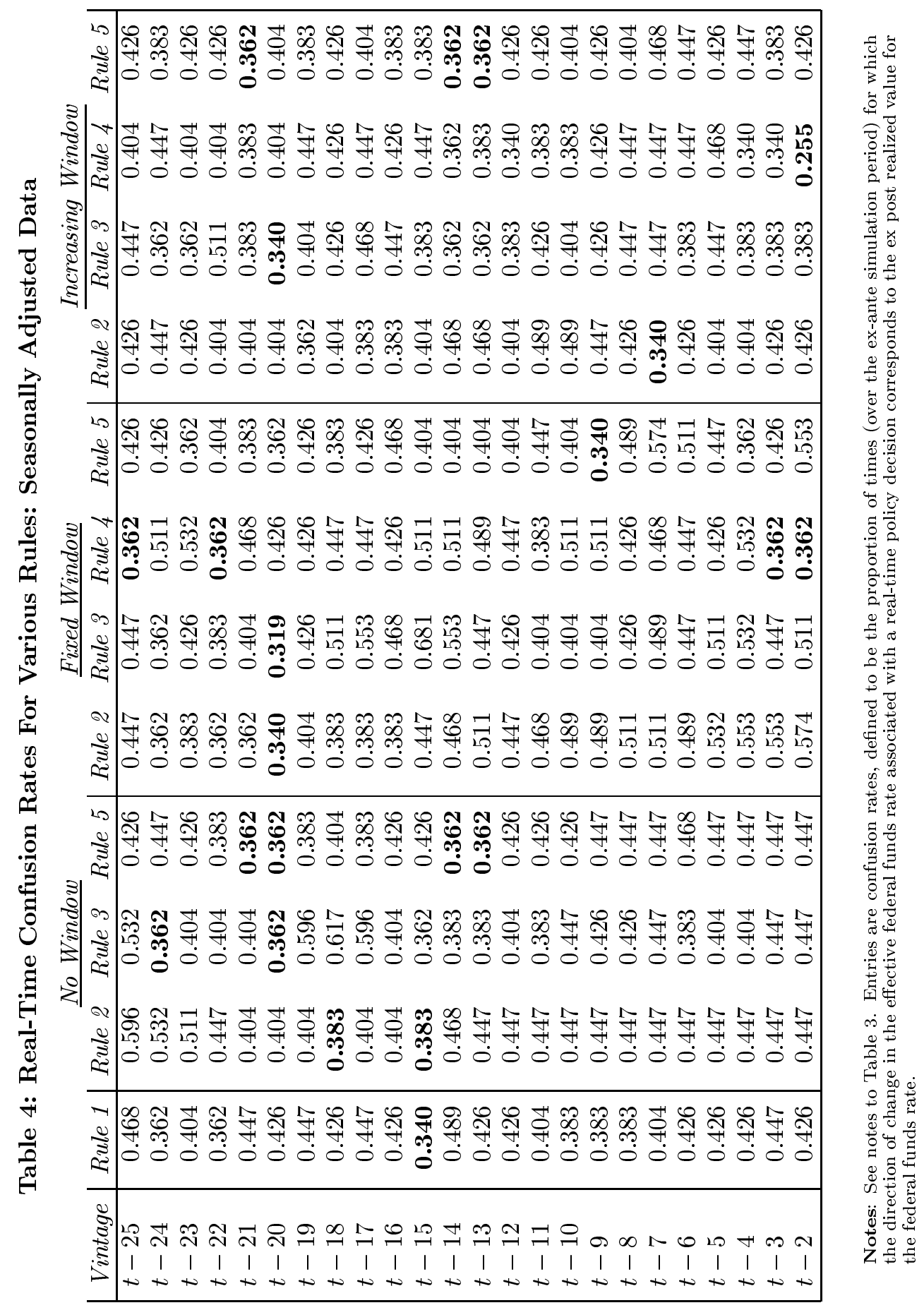




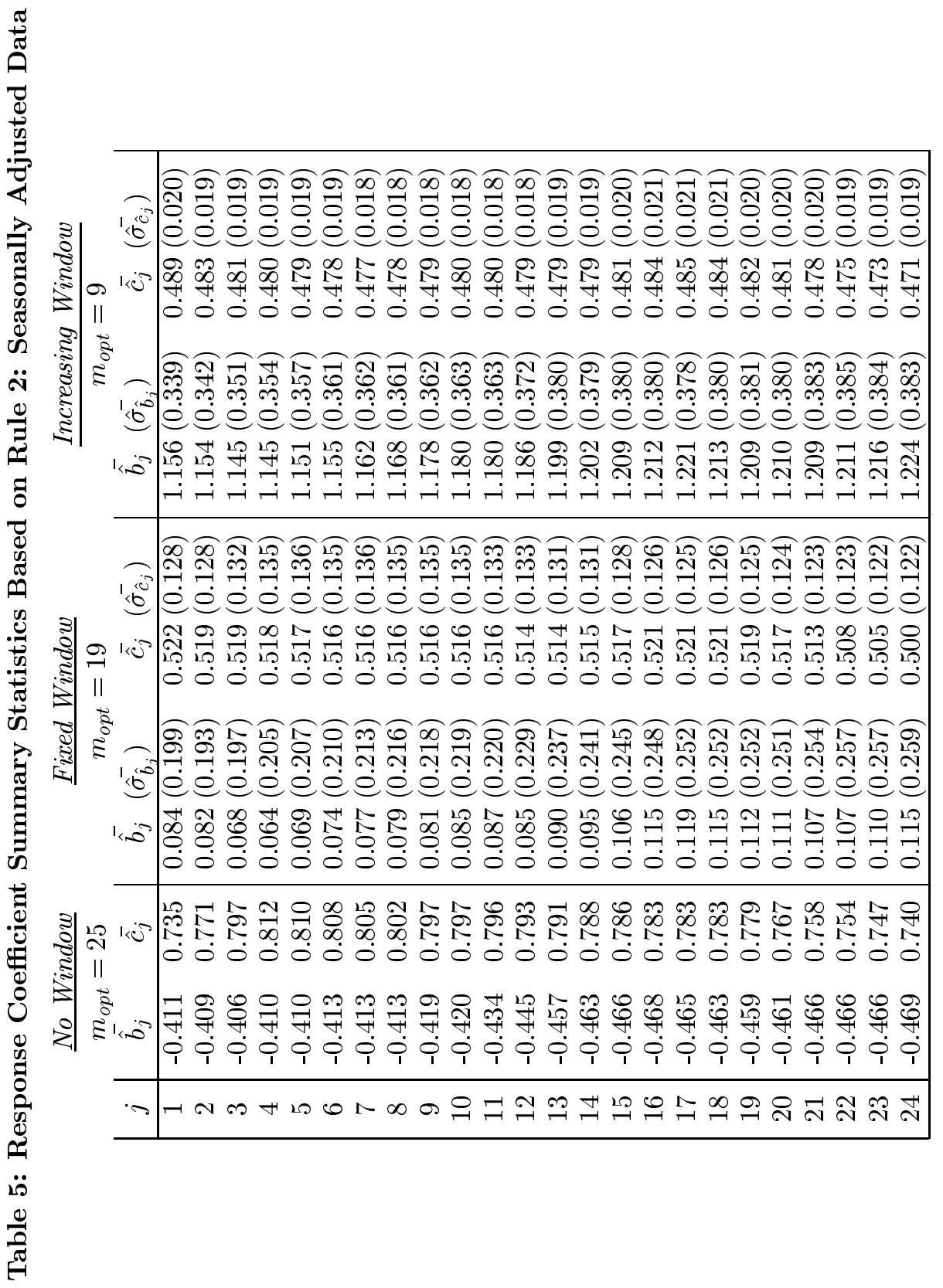




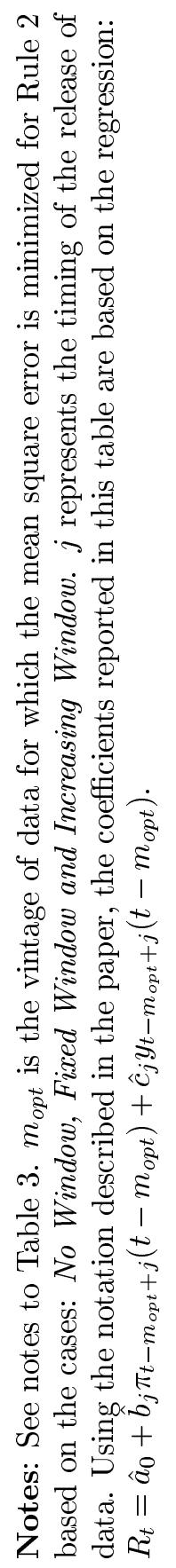




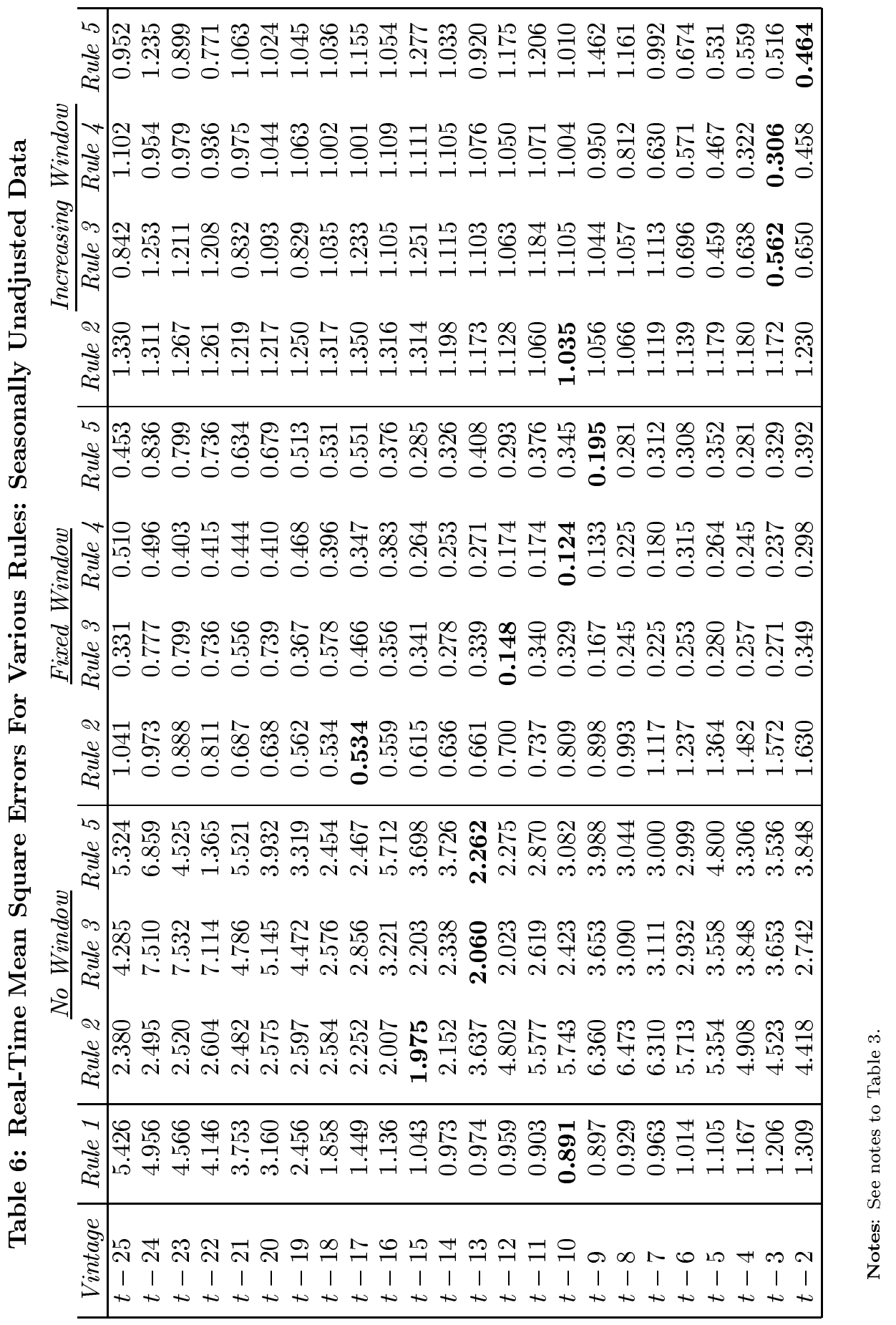




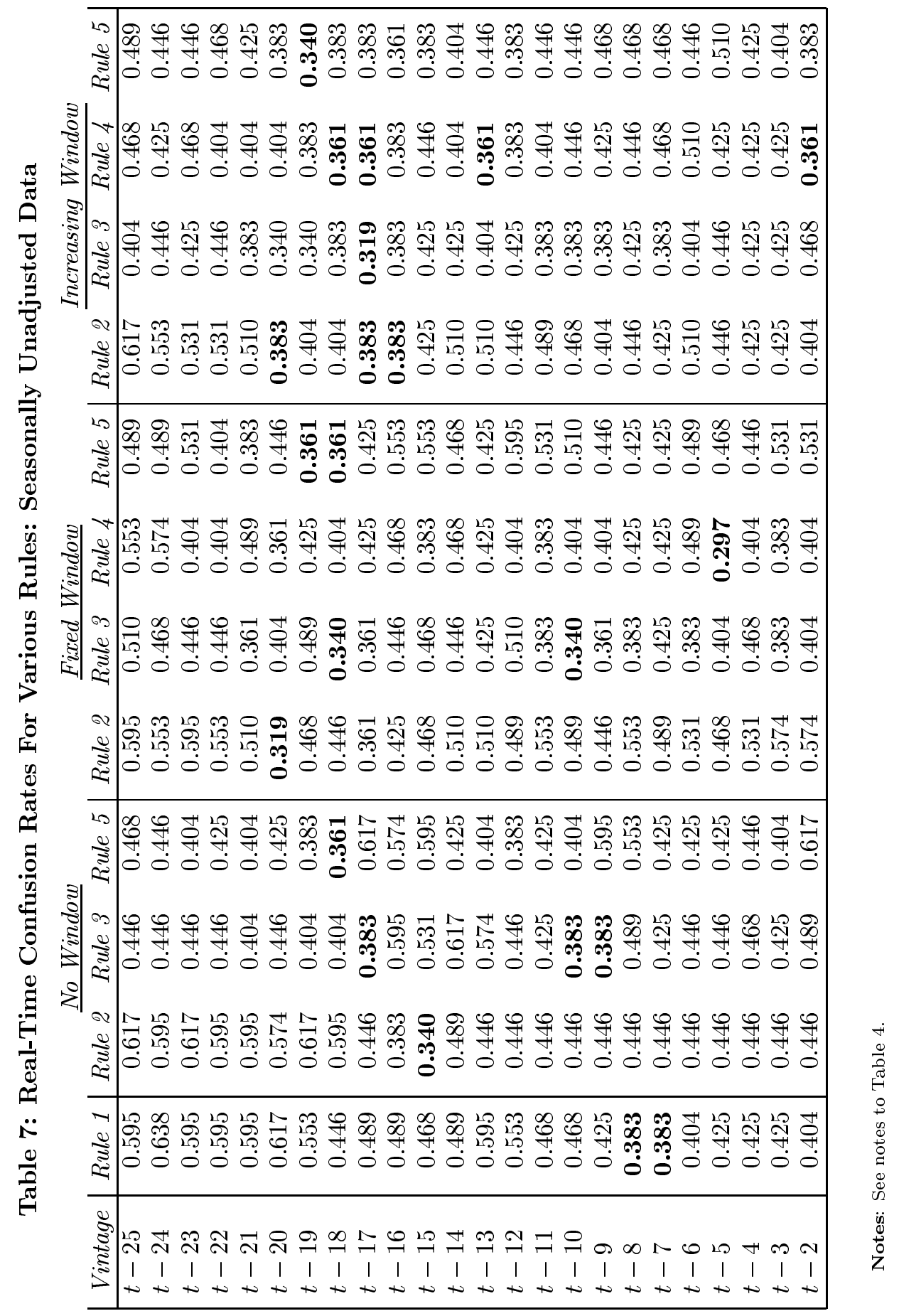




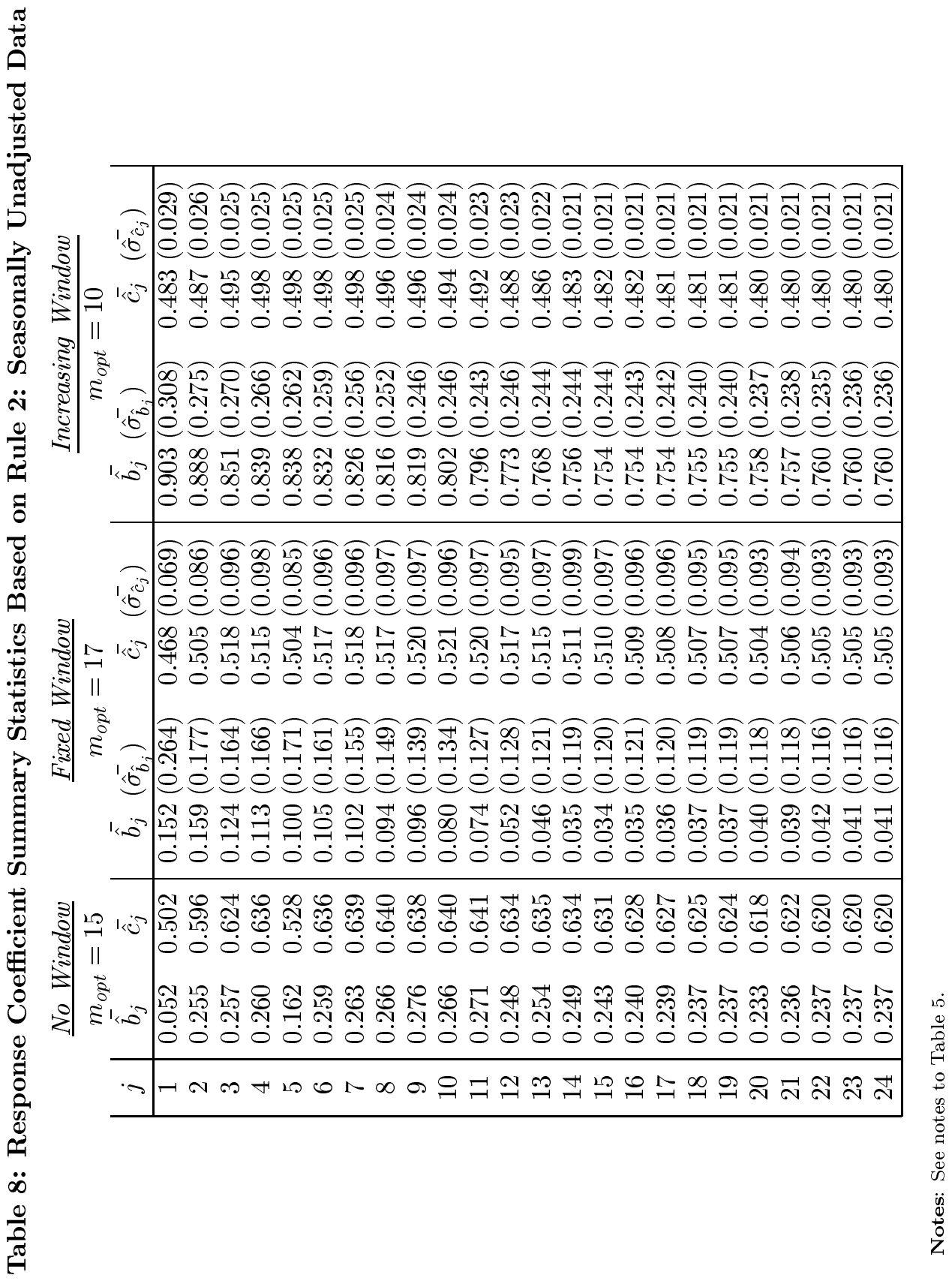


Figure 1: Effective Federal Funds Rate and Simulated Ex-Ante Policy Decisions: 1992:04 to 1996:05.
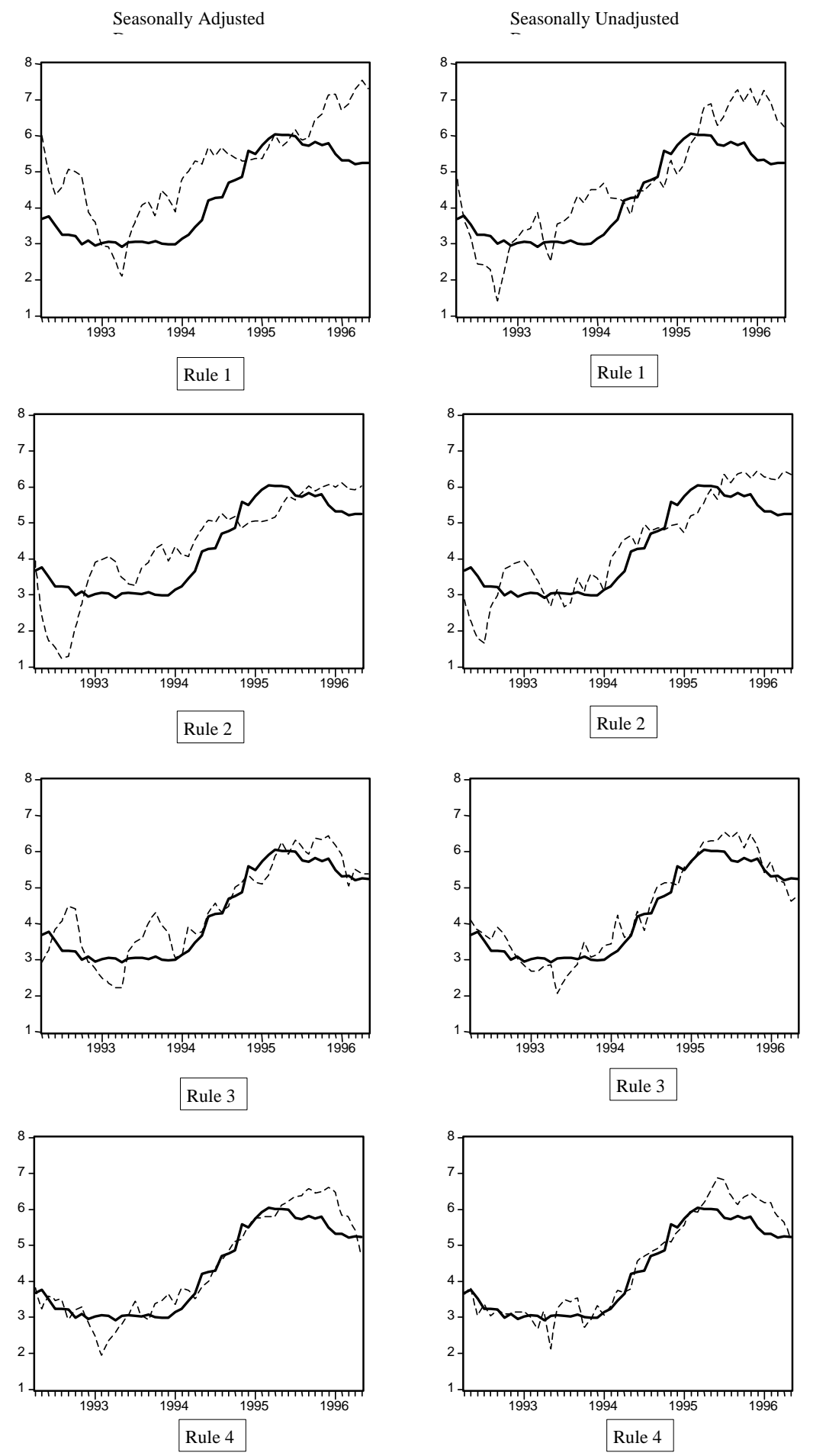

- Effective Federal Funds Rate ---Simulated Ex-Ante Rate

Notes: See Section 4 for a description of the rules. Results are reported for the Fixed Window case and for the 50 month policy simulation period. Rules 2 to 4 are modified real-time versions of a simple ex-ante monetary policy rule which we refer to as Taylor's Rule (Rule 1). 
Figure 2: Effective Federal Funds Rate and Simulated Ex-Ante and Ex-Post Policy Decisions: 1992:04 to 1996:05.
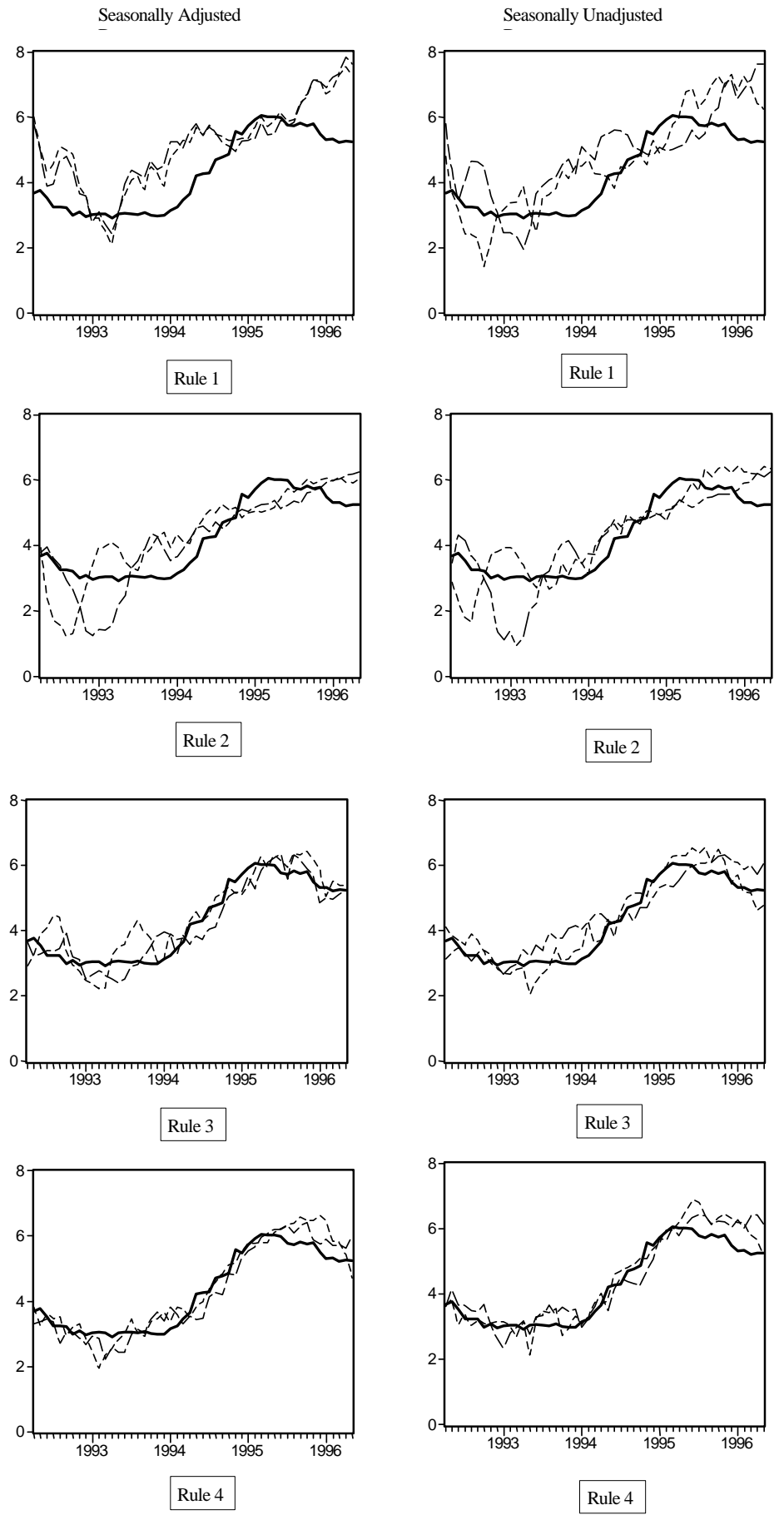

- Effective Federal Funds Rate $\quad$--- Simulated Ex-Ante Rate $\quad--$ Simulated Ex-Post Rate

Notes: See notes to Figure 1. Simulated ex-post federal funds rate values are based on ex-post finalized data. 


\section{Liste des publications au CIRANO *}

\section{Cahiers CIRANO / CIRANO Papers (ISSN 1198-8169)}

96c-1 Peut-on créer des emplois en réglementant le temps de travail ? / Robert Lacroix

95c-2 Anomalies de marché et sélection des titres au Canada / Richard Guay, Jean-François L'Her et Jean-Marc Suret

95c-1 La réglementation incitative / Marcel Boyer

94c-3 L'importance relative des gouvernements : causes, conséquences et organisations alternative / Claude Montmarquette

94c-2 Commercial Bankruptcy and Financial Reorganization in Canada / Jocelyn Martel

94c-1 Faire ou faire faire : La perspective de l'économie des organisations / Michel Patry

\section{Série Scientifique / Scientific Series (ISSN 1198-8177)}

98s-40 Monetary Policy Rules with Model and Data Uncertainty / Eric Ghysels, Norman R. Swanson et Myles Callan

98s-39 Environmental Risks: Should Banks Be Liable? / Karine Gobert et Michel Poitevin

98s-38 Better Observability Promotes the Adoption of More Flexible Technologies / Marcel Boyer, Armel Jacques et Michel Moreaux

98s-37 Job Characteristics, Wages and the Employment Contract / W. Bentley MacLeod et Daniel Parent

98s-36 Observability, Commitment and Flexibility / Marcel Boyer, Armel Jaques et Michel Moreaux

98s-35 Pricing ang Hedging Derivative Securities with Neural Networks and a Homogeneity Hint / René Garcia et Ramazan Gençay

98s-34 Gender Composition and Wages: Why Is Canada Different from the United States? / Michael Baker et Nicole M. Fortin

98s-33 Effects of the Fiscal Treatment of Tax Losses on the Efficiency of Markets and the Incidence of Mergers / Michel Poitevin

98s-32 Travail pendant les études et abandon scolaire : Causes, conséquences, et politiques d'intervention / Marcel Dagenais, Claude Montmarquette, Daniel Parent, Benoit Durocher et François Raymond

98s-31 Collusive Allocation of Tradeable Pollution permits / Ngo Van Long et Antoine Soubeyran

98s-30 Pollution, Pigouvian Taxes, and Asymmetric International Oligopoly / Ngo Van Long et Antoine Soubeyran

98s-29 Quadratic M-Estimators for ARCH-Type Processes / Nour Meddahi et Éric Renault

98s-28 Explaining Sales Pay Strategy Using Agency, Transaction Cost and Resource Dependence Theories / Michel Tremblay, Jérôme Côté et David B. Balkin

98s-27 The Moderating Effect of Job Characteristics on Managers' Reactions to Career Plateau / Michel Tremblay et Alain Roger

* Vous pouvez consulter la liste complète des publications du CIRANO et les publications elles-mêmes sur notre site World Wide Web à l'adresse suivante :

http://www.cirano.umontreal.ca/publication/page1.html 